\title{
Development and evaluation of the aerosol dynamics and gas phase chemistry model ADCHEM
}

\author{
P. Roldin ${ }^{1}$, E. Swietlicki ${ }^{1}$, G. Schurgers ${ }^{2}$, A. Arneth ${ }^{2,3}$, K. E. J. Lehtinen ${ }^{4,5}$, M. Boy ${ }^{6}$, and M. Kulmala ${ }^{6}$ \\ ${ }^{1}$ Division of Nuclear Physics, Lund University, 221 00, Lund, Sweden \\ ${ }^{2}$ Department of Earth and Ecosystem Sciences, Lund University, Sweden \\ ${ }^{3}$ Institute of Meteorology and Climate Research/Atmospheric Environmental Research, \\ Karlsruhe Institute of Technology, Germany \\ ${ }^{4}$ Department of Physics and Mathematics, University of Eastern Finland, Kuopio, Finland \\ ${ }^{5}$ Finnish Meteorological Institute, Kuopio Unit, Kuopio, Finland \\ ${ }^{6}$ Atmospheric Sciences Division, Department of Physics, University of Helsinki, Finland
}

Received: 14 July 2010 - Published in Atmos. Chem. Phys. Discuss.: 10 August 2010

Revised: 16 May 2011 - Accepted: 30 May 2011 - Published: 22 June 2011

\begin{abstract}
The aim of this work was to develop a model suited for detailed studies of aerosol dynamics, gas and particle phase chemistry within urban plumes, from local scale $\left(1 \times 1 \mathrm{~km}^{2}\right)$ to regional scale. This article describes and evaluates the trajectory model for Aerosol Dynamics, gas and particle phase CHEMistry and radiative transfer (ADCHEM). The model treats both vertical and horizontal dispersion perpendicular to an air mass trajectory (2-space dimensions). The Lagrangian approach enables a more detailed representation of the aerosol dynamics, gas and particle phase chemistry and a finer spatial and temporal resolution compared to that of available regional 3D-CTMs. These features make it among others well suited for urban plume studies. The aerosol dynamics model includes Brownian coagulation, dry deposition, wet deposition, in-cloud processing, condensation, evaporation, primary particle emissions and homogeneous nucleation. The organic mass partitioning was either modeled with a 2-dimensional volatility basis set (2D-VBS) or with the traditional two-product model approach. In ADCHEM these models consider the diffusion limited and particle size dependent condensation and evaporation of 110 and 40 different organic compounds respectively. The gas phase chemistry model calculates the gas phase concentrations of 61 different species, using 130 different chemical reactions. Daily isoprene and monoterpene emissions from European forests were simulated separately with the vegetation model LPJ-GUESS, and included as in-
\end{abstract}

Correspondence to: P. Roldin

(pontus.roldin@nuclear.lu.se) put to ADCHEM. ADCHEM was used to simulate the ageing of the urban plumes from the city of Malmö in southern Sweden (280000 inhabitants). Several sensitivity tests were performed concerning the number of size bins, size structure method, aerosol dynamic processes, vertical and horizontal mixing, coupled or uncoupled condensation and the secondary organic aerosol formation. The simulations show that the full-stationary size structure gives accurate results with little numerical diffusion when more than 50 size bins are used between 1.5 and $2500 \mathrm{~nm}$, while the movingcenter method is preferable when only a few size bins are selected. The particle number size distribution in the center of the urban plume from Malmö was mainly affected by dry deposition, coagulation and vertical dilution. The modeled PM2.5 mass was dominated by organic material, nitrate, sulfate and ammonium. If the condensation of $\mathrm{HNO}_{3}$ and $\mathrm{NH}_{3}$ was treated as a coupled process ( $\mathrm{pH}$ independent) the model gave lower nitrate PM2.5 mass than if considering uncoupled condensation. Although the time of ageing from that SOA precursors are emitted until condensable products are formed is substantially different with the 2D-VBS and two product model, the models gave similar total organic mass concentrations.

\section{Introduction and background}

Since the chemical and physical properties of aerosol particles determine both their climate and health effects, it is important to understand the aerosol dynamic processes that affect these quantities. Particle emissions within a city may

Published by Copernicus Publications on behalf of the European Geosciences Union. 
have a significant effect on the population health and climate several tens or hundreds of kilometers downwind of the urban center, although limited quantitative information is available in the literature (Hodzic et al., 2006; Doran et al., 2007; Nolte et al., 2008; Hodzic et al., 2009; Tsimpidi et al., 2010; Wang et al., 2010). The chemical composition of the ambient aerosols is affected by primary particle emissions, condensation, evaporation and coagulation between particles with different composition. The particle number size distribution is altered by emissions, condensation, evaporation, coagulation, dry and wet deposition, formation of new particles by homogeneous nucleation and in-cloud processing.

Since 2007 the trajectory model for Aerosol Dynamics, gas and particle phase CHEMistry and radiative transfer (ADCHEM) has continuously been developed and used at Lund University. In this work ADCHEM was used to model the particle and gas phase properties in the urban plume from the city of Malmö in southern Sweden $\left(13^{\circ} 00^{\prime} \mathrm{E}, 55^{\circ} 36^{\prime} \mathrm{N}\right.$, 280000 inhabitants). This article mainly describes the model development and evaluation, while Paper II (Roldin et al., 2011) describes the average particle and gas phase properties within the urban plume from Malmö, and their influence on the radiation balance and cloud properties.

ADCHEM includes both vertical and horizontal dispersion perpendicular to an air mass trajectory (2-space dimensions), which is not treated in Lagrangian box-models (0space dimensions). The Lagrangian approach allows a more detailed representation of the aerosol dynamics, particle and gas phase chemistry and a finer spatial and temporal resolution than available in regional three-dimensional chemical transport models (3D-CTMs). These features make it well suited both for studies of urban plumes as well as long distance transported air masses (e.g. studies of regional new particle formation events). The disadvantage with Lagrangian models is that they follow one air mass trajectory, and do not account for different wind speed or wind directions at different altitudes. Hence, these models have limitations in some meteorological conditions, and if the emissions within a source region (e.g. a city) show rapid and large temporal variability (see discussion in Sect. 2.1).

Aerosol models can be divided into equilibrium models and dynamic models. The equilibrium models assume equilibrium between the gas and particle phase while dynamic models treat the mass transport between gas and particle phase. Due to computational limitations the detailed aerosol inorganic chemistry models are primarily equilibrium models, e.g. AIM (Wexler and Clegg, 2002), while aerosol dynamics models usually use a more simplified particle chemistry, e.g. UHMA (Korhonen et al., 2004b), or no particle chemistry, e.g. AEROFOR (Pirjola, 1999) and MONO32 (Pirjola et al., 2003).

Once introducing particle chemistry into the aerosol dynamics model it should preferably be coupled to a detailed gas phase chemistry model. One such early study was performed by Pirjola and Kulmala (1998), which modeled bi- nary $\mathrm{H}_{2} \mathrm{SO}_{4}-\mathrm{H}_{2} \mathrm{O}$ nucleation in urban and rural environments, using a box model. Fitzgerald et al. (1998) developed the MARBLES model, which is a one dimensional (1-D) Lagrangian aerosol dynamics model developed to simulate multicomponent (sulfuric acid, sea salt and crustal material) aerosol composition in the marine boundary layer. However, this model did not include a detailed gas phase chemistry model.

Boy et al. (2006) were among the first to include a detailed aerosol dynamics model (UHMA) together with a detailed gas phase chemistry model and a meteorological model in 1-D (vertical). This model named MALTE is primarily designed to model new particle formation in the lower troposphere. ADCHEM developed in this work has many similarities with MALTE concerning the aerosol dynamics, gas phase chemistry and dispersion in the vertical direction. In ADCHEM a second horizontal space dimension was introduced to enable the simulation of horizontal inhomogeneous emissions in urban plumes. However, ADCHEM does not include any meteorological model, and therefore relies on meteorological input data along the trajectory. ADCHEM also incorporates a detailed radiative transfer model which treats scattering and absorption from gases, particles and clouds (Toon et al., 1989). The gas phase model included in ADCHEM is developed from the kinetic code incorporated in the model developed by Pirjola and Kulmala (1998).

Recently aerosol dynamics models which treat condensation and evaporation of semi-volatile inorganic gases like ammonia $\left(\mathrm{NH}_{3}\right)$, nitric acid $\left(\mathrm{HNO}_{3}\right)$ and hydrochloric acid ( $\mathrm{HCl})$ have been developed (e.g. Zhang and Wexler, 2008). These models can treat the acid and base mass transfer either as separate processes or simplified as a coupled process. The large advantage of coupling the condensation and evaporation of acid and base (e.g. $\mathrm{HNO}_{3}$ and $\mathrm{NH}_{3}$ ) is that the condensation and evaporation becomes $\mathrm{pH}$ independent, and allows the model to take longer time steps when solving the condensation/evaporation process. The disadvantage with the coupled condensation/evaporation process is that it is only valid if the aerosol is near acid neutrality (Zaveri et al., 2008 and Zhang and Wexler, 2008).

To be able to take long time steps (minutes), without causing oscillatory solutions when solving the condensation/evaporation of acid and base as separate processes, Jacobson (2005a) developed the prediction of non-equilibrium growth (PNG) scheme. With this method the condensation (dissolution) and evaporation of $\mathrm{HNO}_{3}, \mathrm{HCl}$ and $\mathrm{H}_{2} \mathrm{SO}_{4}$ is solved first, depending on the $\mathrm{pH}$ calculated from the previous time step, and then the $\mathrm{NH}_{3}$ dissolution is treated as an equilibrium process. With this method the dissolution of $\mathrm{NH}_{3}$ is linked to the condensation/evaporation of the acids but also depends on the $\mathrm{pH}$ in the aerosol liquid phase. Therefore this method is also valid when the aerosol is not near acid neutralized. In ADCHEM, the condensation and evaporation of $\mathrm{HNO}_{3}, \mathrm{HCl}$ and $\mathrm{NH}_{3}$ can either be treated as coupled or uncoupled processes, and the dissolution of $\mathrm{NH}_{3}$ 
can either be modeled as a dynamic or equilibrium process. ADCHEM also considers in-cloud processing of aerosol particles, including sulfate $(\mathrm{S}(\mathrm{VI}))$ formation from dissolved $\mathrm{SO}_{2}$ and $\mathrm{H}_{2} \mathrm{O}_{2}$. The dissolution of $\mathrm{SO}_{2}$ and $\mathrm{H}_{2} \mathrm{O}_{2}$ are treated as equilibrium processes.

The main objective of this work was to develop a model which can be used for detailed simulations of ageing processes within urban plumes, from local scale $\left(1 \times 1 \mathrm{~km}^{2}\right)$ to regional scale. One application of this comprehensive model which is addressed in this work is to study which processes that are most important for accurate representation of aerosol dynamics and particle chemical composition in urban plumes. These results are useful when developing more simplified aerosol dynamics, gas and particle phase chemistry modules or parameterizations for 3D-CTMs or global climate models.

\section{Model description}

ADCHEM can be divided into three sub-models:

1. an aerosol dynamics and particle chemistry model,

2. a chemical gas phase model,

3. a radiative transfer model.

The aerosol dynamics model in ADCHEM is a sectional model which discretizes the particle number size distribution into finite size bins. The particles are assumed to be internally mixed which means that particles of the same size within the same grid cell have the same composition. The model includes Brownian coagulation, dry deposition, wet deposition, in-cloud processing, condensation, evaporation, primary particle emissions, homogeneous nucleation and dispersion in the vertical (1-D model) and horizontal direction (2-D model) perpendicular to the air mass trajectory. The model treats both organic and inorganic particle phase chemistry with sulfate, nitrate, ammonium, sodium, chloride, non water soluble minerals (metal oxides/hydroxides), soot, Primary Organic Aerosol (POA), Anthropogenic and Biogenic Secondary Organic Aerosol (ASOA and BSOA), and dissolution of sulfur dioxide and hydrogen peroxide into the particles and cloud droplets. In ADCHEM SOA can either be formed by condensation of oxidation products of specific VOCs (e.g. $\alpha$-pinene, $\beta$-pinene, $\Delta 3$-carene, D-limonene, isoprene, benzene, toluene and xylene), using the traditional two-product model (Odum et al., 1996) or using the newly developed volatility basis set (VBS) approach (Donahue et al., 2006), which divides all organic compounds into volatility classes without identifying individual compounds. The aerosol dynamics and particle phase chemistry model is coupled to the gas phase chemistry model through condensation, evaporation and homogeneous nucleation.

The gas phase chemistry model calculates the gas phase concentrations of 61 different species, using 130 different chemical reactions. Daily isoprene and monoterpene emissions from European forests were simulated separately with the vegetation model LPJ-GUESS (Smith et al., 2001 and Sitch et al., 2003), in which processbased algorithms of terpenoid emissions were included (Arneth et al., 2007, Schurgers et al., 2009a). The emissions from natural vegetation were corrected for anthropogenic land cover following Ramankutty et al. (2008), in a way similar to that in Arneth et al. (2008).

The actinic flux used to calculate the photochemical reaction rates, is derived with the radiative transfer model. This model uses a quadrature two-stream approximation scheme, where the radiative fluxes are approximated with one upward and one downward flux component. The model can be used to calculate the radiative transfer in a vertically inhomogeneous atmosphere with clouds and aerosol particles (Toon et al., 1989).

Figure 1 illustrates the model structure in ADCHEM. The model starts by calculating the turbulent diffusivity in the vertical and horizontal direction using meteorological and land use category input data. After this the model starts integrating over time using operator splitting for each individual process (module). Each individual process (module) displayed in Fig. 1 is described in detail below.

To our knowledge there are no other models available like ADCHEM which combine schemes of detailed aerosol dynamics, gas phase chemistry, inorganic particle phase chemistry, dynamic and particle size dependent SOA formation, cloud processing and radiative transfer in two space dimensions in a Lagrangian model with high spatial and temporal resolution $(\sim 1 \mathrm{~km}, \sim 1 \mathrm{~min})$.

Since ADCHEM is a Lagrangian model it relies on separate results from an air mass trajectory model. In this work the air mass trajectory for the studied case was modeled with the Hybrid Single Particle Lagrangian Integrated Trajectory (HYSPLIT) model (Draxler and Rolph, 2011), which was run with meteorological data from the Global Data Assimilation System (GDAS) from National Weather Service's National Centers for Environmental Prediction (NCEP), with a horizontal resolution of $1^{\circ} \times 1^{\circ}$ and a temporal resolution of $3 \mathrm{~h}$.

Stohl et al. (2001) conducted a model comparison between three different air mass trajectory models and concluded that although the average horizontal position deviations was largest close to the surface, it was not larger than $10 \%$ for $48 \mathrm{~h}$ backward trajectory simulations. However, the accuracy of the trajectory model does not just depend on the model structure but also the meteorological input data. Hence, since the HYSPLIT model relies on relatively coarse large scale meteorology data, the wind direction of the modeled trajectory was validated with wind direction measurements in Malmö, at $24 \mathrm{~m}$ a.g.l. For the selected case study the modeled and measured wind direction at this altitude agree within five degrees. 


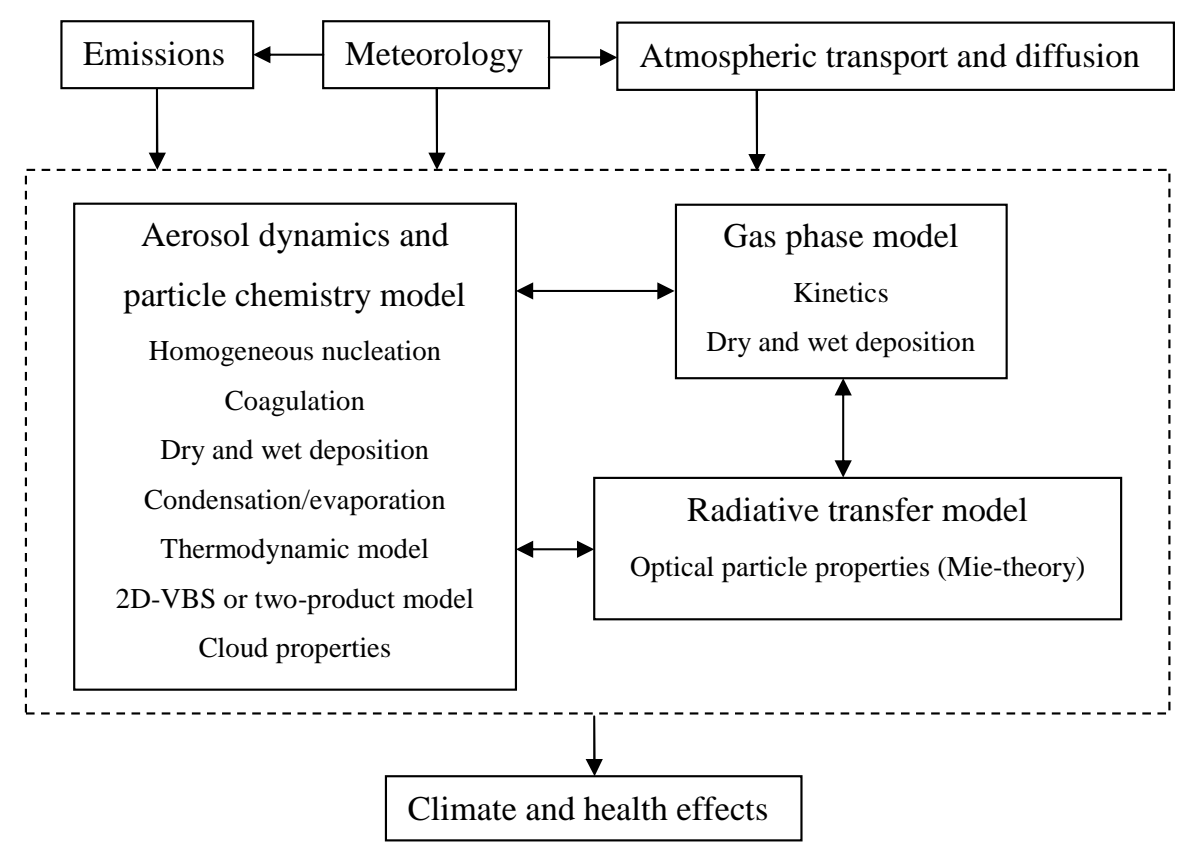

Fig. 1. Schematic picture illustrating the model structure of ADCHEM.

\subsection{Atmospheric diffusion}

For the simulations performed in this study a model domain of 20 vertical grid cells and 20 horizontal grid cells was used. The vertical and horizontal grid resolution was $100 \mathrm{~m}$ and $1000 \mathrm{~m}$ respectively. The 2-D model solves the atmospheric diffusion equation (Eq. 1) in the vertical and horizontal direction perpendicular to the air mass trajectory.

$\frac{d c}{d t}=\frac{\partial}{\partial z}\left(K_{z} \frac{\partial c}{\partial z}\right)+\frac{\partial}{\partial y}\left(K_{y} \frac{\partial c}{\partial y}\right)$

Dry deposition and emissions of primary particles in the surface layer are treated separately, and are not included in the boundary conditions for the atmospheric diffusion equation in order to reduce computing time. Instead of solving the 2-D atmospheric diffusion equation for each particle size bin, for 8 inorganic and up to 110 organic aerosol compounds, and each gas phase species (61 compounds), the model solves the atmospheric diffusion equation once for each grid cell. This is possible because the transport of compounds by turbulent diffusivity in contrast to e.g. molecular diffusion is independent of the properties of the individual species. For the $20 \times 20$ grid, the diffusion equation has to be solved 400 times in each time step. Equation (1) is solved 400 times by introducing an inert species with initial concentration equal to 1 , in one new single grid cell at the time. In all other grid cells the concentration is set to zero. After one time step a new concentration matrix of the inert species is received, which describes the mixing of the air between the grid cell with initial concentration equal to 1 and the surrounding grid cells. If the time step used is short enough the atmospheric diffusion equation does not have to be solved for the whole grid, but rather for the grid cells closest to the grid cell with an initial concentration equal to 1 . This way the simulation time can be decreased drastically.

$K_{z}$ and $K_{y}$ in Eq. (1) are the eddy diffusivities (turbulent diffusivities) in the vertical and horizontal direction respectively and $c$ is the concentration of any arbitrary species. The eddy diffusivities are calculated for stable, neutral and unstable atmospheric conditions using the representations from Businger and Arya (1974), Myrup and Ranzieri (1976) and Tirabassi and Rizza (1997) (Appendix A). The three turbulence regimens are defined by the dimensionless parameter $(h / L)$, where $h$ is the mixing height and $L$ is the MoninObukov length, which describes the relationship between the buoyant and wind shear produced turbulent kinetic energy. For stable conditions the turbulence in the boundary layer is mainly produced by wind shear while for unstable conditions the turbulence is mainly induced by buoyant convection. Hence, for stable and neutral conditions the eddy diffusivity is represented by expressions which depend on the friction velocity while for unstable conditions the friction velocity is replaced with the convective velocity (see Appendix A).

The numerical solution of the atmospheric diffusion equation is described in Appendix B. As upper boundary condition the concentration gradient $\partial c / \partial z$ was set to $10^{-3} \mathrm{~cm}^{-3} \mathrm{~m}^{-1}$ to account for the generally decreasing gas and particle concentrations above the model domain ( $2000 \mathrm{~m}$ a.g.1.). This is a rough assumption which could not be verified with measurements. However, because of the 
vertical stability above the boundary layer it had negligible influence on the concentrations within the boundary layer. As horizontal boundary conditions the concentration gradient $\partial c / \partial y$ was set to zero.

ADCHEM does not consider advection in the horizontal direction perpendicular to an air mass trajectory or that the wind speed may change in the vertical direction. This is the largest disadvantage with the model compared to Eulerian 3D-models. Hence, ADCHEM cannot be used to accurately simulate urban plumes when the wind direction changes significantly in the vertical direction within the boundary layer. The model results are also distorted if the wind speed changes in the vertical direction, but this is mainly a problem if the emissions within the city changes significantly and rapidly. Wind shear changes the wind direction and the wind speed in the vertical direction, while the vertical diffusion prevents these distortions (Tirabassi and Rizza, 1997). Hence, it is during stable conditions (strong wind shear and slow vertical diffusion) that ADCHEM may be less appropriate for urban plume simulations. At long distances downwind of the starting point there will always be some divergence between the air mass trajectories at different altitudes which limits the spatial coverage of Lagrangian models. Hence, the model accuracy for urban plume studies generally deteriorates with the distance downwind of the source region. ADCHEM is therefore mainly useful when studying the first few hours up to possibly one day of ageing downwind of a city. When studying large scale regional air mass transport without the influence from large point sources (e.g. cities) the Lagrangian model approach can however be useful on larger spatial scales (several days) (see e.g. Tunved et al., 2010).

Figure S1 in the Supplement illustrates how different HYSPLIT air mass trajectories which start over Malmö at different altitudes but at the same time, are separated from each other due to different wind speed and wind direction at different altitudes. At Vavihill the trajectories which start at 50 and $300 \mathrm{~m}$ a.g.l. over Malmö are separated approximately $5 \mathrm{~km}$ in the horizontal direction, due to wind shear in the stable stratified boundary layer. The trajectory which starts $500 \mathrm{~m}$ a.g.l. over Malmö (above the boundary layer) passes approximately $10 \mathrm{~km}$ to the east of Vavihill.

\subsection{Aerosol dynamics}

Each aerosol dynamic process is included as a separate process in the model, using operator splitting. As default the model solves all aerosol dynamic processes with a time interval of $60 \mathrm{~s}$.

\subsubsection{Size distribution structures}

In ADCHEM the changes in the size distributions upon condensation/evaporation or coagulation are solved with the fullstationary, full-moving or moving-center structures which all have different advantages and disadvantages. All these methods are mass and number conserving, which was tested before the methods were implemented in ADCHEM. For a detailed description of the methods see Sect. 13 in Jacobson (2005b).

If using the full-stationary structure when calculating how the particle number size distribution changes in diameter space, the so called splitting procedure has to be used. With this procedure it is assumed that only a fraction of the particles in one size bin will grow to the next size bin, while the rest of the particles will not grow at all (Korhonen, 2004b). This leads to numerical diffusion which makes the particle number size distribution wider and the peak concentration lower (Jacobson, 2005b and Korhonen, 2004b). The reason for this is that splitting makes some particles grow more than in the reality, while others will not grow at all. The numerical diffusion can be decreased by increasing the number of size bins (Korhonen, 2004b).

With the full-moving structure the particles are allowed to grow to their exact size and instead of splitting them back onto a fixed diameter grid the diameter grid moves with the particles. While eliminating the numerical diffusion this causes problems if air mixes between adjacent grid cells and if considering new particle formation. Therefore the fullmoving structure will not be used in this study.

The moving-center method is a combination of the fullstationary structure and the full-moving structure. The particles are allowed to grow to their exact size as long as they are not crossing the fixed diameter bin limits. If the particles in a size bin cross the lower or upper diameter limit they are all moved to the adjacent diameter bin and their volume is averaged with the particles in the new bin, which then get a new diameter. Since all the particles in one size bin move to a new bin in the same time step the numerical diffusion is minimized when using the moving-center structure. Therefore this method is preferable when the size distribution is represented by only a few size bins.

\subsubsection{Condensation and evaporation}

ADCHEM considers the condensation and evaporation of sulfuric acid, ammonia, nitric acid, hydrochloric acid and oxidation products of different organic compounds. Figure 2 illustrates the structure of the condensation/evaporation algorithm used in ADCHEM. The condensation and evaporation is solved by first calculating the single particle molar condensation growth rate of each compound, for each size bin separately (Eq. 2). If considering uncoupled condensation of acids and ammonia the analytic prediction of condensation (APC) scheme and predictor of non-equilibrium growth (PNG) scheme developed and described in detail by Jacobson $(1997,2005 a)$ are used, while if treating the condensation of acids and ammonia as a coupled process the method first proposed by Wexler and Seinfeld (1990) and later applied by e.g. Zhang and Wexler (2008) is used. The coupled 
condensation growth rate of $\mathrm{NH}_{3}$ and $\mathrm{HX}\left(\mathrm{mol} \mathrm{s}^{-1}\right)$ is given by Eq. (3), where $X$ denotes either $\mathrm{Cl}$ or $\mathrm{NO}_{3}$. The total $\mathrm{NH}_{3}$ condensation growth rate $\left(I_{\mathrm{NH}_{3}}\right)$ is then given by the sum of the $\mathrm{HCl}, \mathrm{HNO}_{3}$ and 2 times the $\mathrm{S}(\mathrm{VI})$ condensation growth rates $\left(I_{\mathrm{NH}_{3}}=2 I_{\mathrm{S}(\mathrm{VI})}+I_{\mathrm{HNO}_{3}}+I_{\mathrm{HCl}}\right)$. Both methods are mass and number conserving when combined with either the full-stationary, full-moving or moving-center structure. The APC scheme is used for condensation/evaporation of organic compounds, sulfuric acid and for $\mathrm{HCl}$ and $\mathrm{HNO}_{3}$ if they form solid salts with ammonium, while for dissolution of $\mathrm{HCl}$ and $\mathrm{HNO}_{3}$ into the particle water phase, the PNG scheme is used instead (Jacobson, 2005a). In this scheme dissolution of ammonia is treated as an equilibrium process solved after the diffusion limited condensation/evaporation of $\mathrm{HNO}_{3}, \mathrm{HCl}$ and $\mathrm{H}_{2} \mathrm{SO}_{4}$. Treating the dissolution of $\mathrm{NH}_{3}$ as an equilibrium process enables the model to take long time steps (minutes) when solving the condensation/evaporation process (Jacobson, 2005a). This method can easily be modified to treat the ammonia dissolution as a dynamic process. However, this requires that the time step is decreased drastically to prevent oscillatory solutions.

$$
\begin{aligned}
& I_{i}=2 D_{i} D_{\mathrm{p}} f_{i}\left(\mathrm{Kn}_{i}, \alpha_{i}\right)\left(C_{i \infty}-C_{i s}\right) \\
& f_{i}\left(\mathrm{Kn}_{i}, \alpha_{i}\right)=\frac{0.75 \alpha_{i}\left(1-\mathrm{Kn}_{i}\right)}{\mathrm{Kn}_{i}^{2}+\mathrm{Kn}_{i}+0.283 \mathrm{Kn}_{i} \alpha_{i}+0.75 \alpha_{i}} \\
& I_{\mathrm{HX}}=\frac{\pi D_{\mathrm{p}} \overline{D C}}{f_{\mathrm{NH}_{3}}}\left(1-\sqrt{1-\frac{4 f_{\mathrm{NH}_{3}}^{2}\left(C_{\mathrm{NH}_{3}, \infty} C_{\mathrm{HX}, \infty}-C_{\mathrm{NH}_{3}, s} C_{\mathrm{HX}, s}\right)}{\bar{C}^{2}}}\right) \\
& \bar{D}=\sqrt{D_{\mathrm{NH}_{3}} D_{\mathrm{HX}}} \\
& \bar{C}=\left(D_{\mathrm{NH}_{3}} C_{\mathrm{NH}_{3}}+D_{\mathrm{HX}} C_{\mathrm{NH}_{3}}\right) / \bar{D}
\end{aligned}
$$

In Eqs. (2) and (3) $I_{i} i$ to the molar growth rates, $f_{i}$ is the Fuchs-Sutugin correction factor in the transition region, $C_{i, \infty}$ is the gas phase concentration of species $i$ (moles $\mathrm{m}^{-3}$ air) far from the particle surface, $C_{i, s}$ is the saturation gas phase concentration at the particle surface, $D_{\mathrm{p}}$ is the particle diameter, $\mathrm{Kn}_{i}$ is the non-dimensional Knudsen number and $\alpha_{i}$ is the mass accommodation coefficient. The mass accommodation coefficients for $\mathrm{HNO}_{3}, \mathrm{NH}_{3}, \mathrm{H}_{2} \mathrm{SO}_{4}, \mathrm{HCl}, \mathrm{SO}_{2}, \mathrm{H}_{2} \mathrm{O}_{2}$ and all condensable organic compounds were set to $0.2,0.1$, $1.0,0.2,0.11,0.23$ and 0.1 , respectively. For the inorganic compounds these numbers are within the range of values tabulated in Sander et al. (2006) over liquid water at temperatures between 260 and $300 \mathrm{~K}$. As a sensitivity test one simulation was also performed with unity mass accommodation coefficients. Usually it is assumed that the saturation vapor pressure of sulfuric acid is zero (Korhonen, 2004a and Pirjola and Kulmala, 1998). The saturation vapor concentrations of ammonia, nitric acid and hydrochloride acid and the equilibrium concentration of sulfuric acid and hydrogen peroxide are calculated using a thermodynamic model described in Sect. 2.2.8. For the organic compounds the saturation vapor concentrations $\left(C_{i, s}\right)$ are derived with the 2D-VBS method or the two-product model (see Sect. 2.4), while the actual gas phase concentrations $\left(C_{i, \infty}\right)$ are saved and updated continuously as separate variables.

The VBS approach (Donahue et al., 2006) and the twoproduct model (Odum et al., 1996), are based on the partitioning theory from Pankow (1994), which describes the equilibrium gas and particle phase partitioning of organic vapors (see Sect. 2.4). When the VBS model is applied, ADCHEM considers the kinetic (diffusion limited) condensation/evaporation of 110 different organic compounds, while when the two-product model is used the number of condensable organic compounds is 40 . Both methods take into account the Kelvin effect and give a particle size dependent partitioning of the different condensable organic compounds, with larger fraction of low volatile compounds found on the smaller particle sizes and a larger fraction of more volatile compounds found on the larger particle sizes. This kinetic and particle size dependent condensation/evaporation requires that ADCHEM keeps track of all the different organic compounds in each particle size bin, which is computationally expensive, especially for the coagulation algorithm.

\subsubsection{Coagulation}

Coagulation has no direct influence on the total particle mass but is important for the total number concentration, the particle number size distribution and the chemical composition distribution, especially for conditions with high number concentrations of nucleation mode particles and a large accumulation mode which the nucleation mode particles can coagulate onto. In cities such conditions can be found in street canyons near the vehicle emissions. Here coagulation is usually the most important aerosol dynamic process (Jacobson and Seinfeld, 2004). The model used in this article treats primary particle emissions occurring on a spatial resolution of $1 \times 1 \mathrm{~km}^{2}$ and not on the street canyon spatial scale (1$100 \mathrm{~m}$ ). To account for the initial ageing of the primary particle emissions real-world emission size distributions were used, which take into account the first minutes of ageing from street-canyon to urban background (see Sect. 2.2.5). This decreases the influence of coagulation on the modeled particle number size distribution, but still coagulation needs to be considered for the transformation of the particle number size distribution on longer time scales (hours). The solution of the Brownian coagulation equations is given in Appendix C. Independently if using the full-stationary or moving-center structure, splitting needs to be used to fit the particles back onto the diameter grid.

\subsubsection{Dry and wet deposition of particles}

The dry deposition of particles is treated as a separate process after the atmospheric diffusion equation has been solved. The dry deposition velocities over land are calculated using a resistance model based on the model by Slinn (1982) (modified by Zhang et al., 2001), while over the ocean the model 


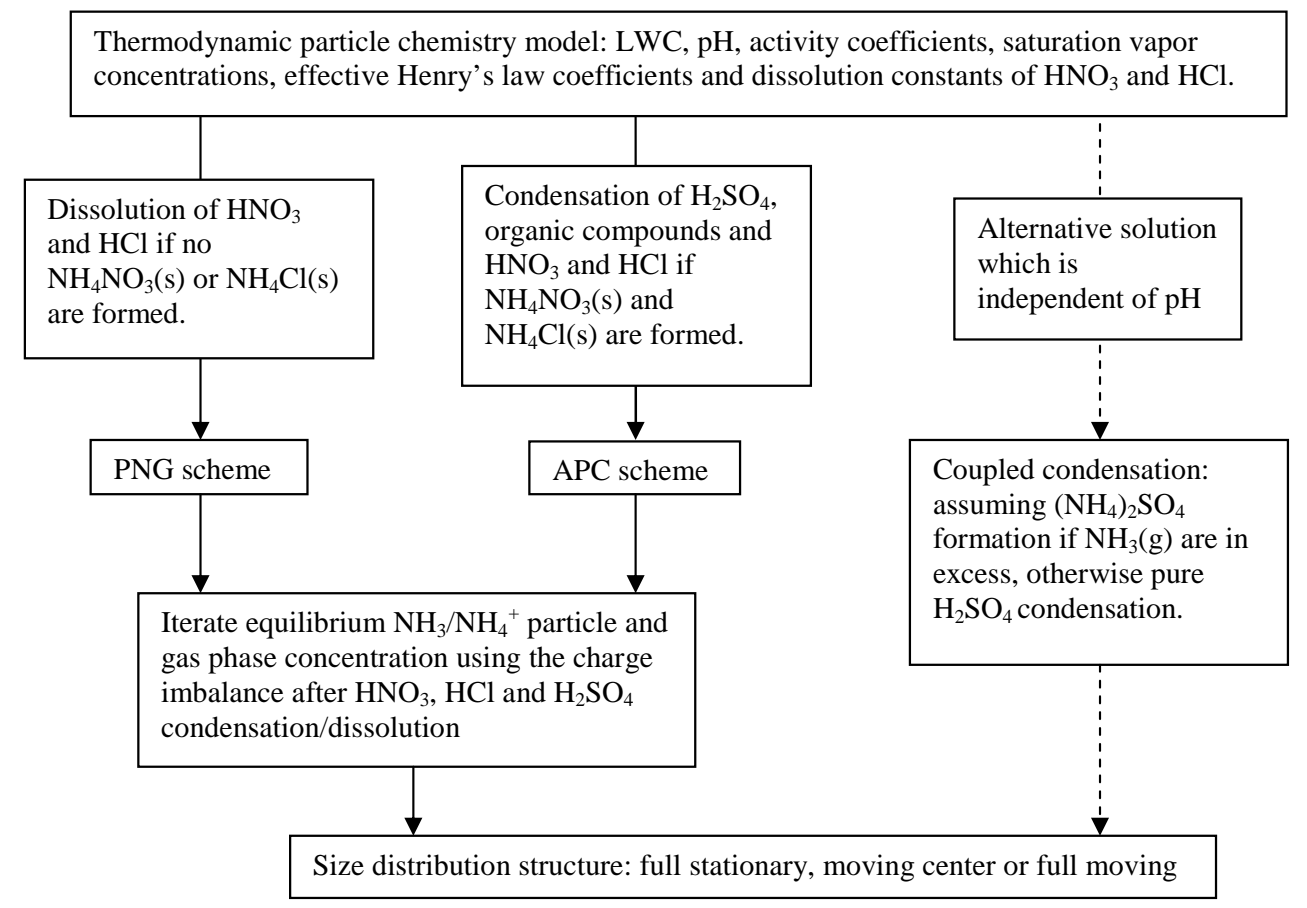

Fig. 2. Schematic picture illustrating the condensation module used in ADCHEM.

by Slinn and Slinn (1980) is used. The particle transport is governed by three resistances in series, the surface layer resistance $\left(r_{a}\right)$, the quasi-laminar layer resistance $\left(r_{b}\right)$ and the surface resistance or canopy resistance $\left(r_{c}\right)$. The dry deposition velocity for large particles also depends on the settling velocity $\left(v_{s}\right)$. If particle losses due to impaction, interception and diffusion are considered to take place in the quasilaminar layer, the surface resistance can be neglected (Seinfeld and Pandis, 2006). The dry deposition velocity representation is given in Appendix D.

The wet deposition rates $\left(\mathrm{s}^{-1}\right)$ of different particle sizes are calculated according to the parameterization by Laakso et al. (2003), derived from $6 \mathrm{yr}$ of measurements at Hyytiälä field station in southern Finland. The only input to the wet deposition parameterization apart from the particle diameter is the rainfall intensity in $\mathrm{mm} \mathrm{h}^{-1}$. Wet deposition removal of particles is considered for all grid cells below the estimated cloud base and the rainfall intensity was assumed to be constant in the horizontal direction perpendicular to the air mass trajectory. Hence, if the estimated cloud base is above the model domain (more than $2 \mathrm{~km}$ a.g.l.) the wet deposition rate is constant within the whole model domain.

\subsubsection{Primary particle emissions}

Equivalent to the dry deposition the primary particle emissions in the surface layer are treated as a separate process after the atmospheric diffusion equation has been solved. Primary particle emissions included in the model are:
1. marine aerosol emissions,

2. non-industrial combustion,

3. road traffic emissions,

4. ship emissions.

The marine aerosol particle emissions are calculated using the emission parameterization from Mårtensson et al. (2003). The marine particle chemical composition is assumed to be composed of sodium chloride $(\mathrm{NaCl})$ and $\mathrm{POA}$, with $\mathrm{NaCl}$ dominating in the coarse mode and organic material dominating in the nucleation and Aitken mode, according to the size resolved chemical analysis of marine aerosol particles at Mace Head during the biological active period (spring, summer and autumn) (O'Dowd et al., 2004).

Size resolved anthropogenic primary particle emissions from non industrial combustion and ship traffic are estimated from PM2.5 mass emissions, by applying an assumed effective particle density of $1000 \mathrm{~kg} \mathrm{~m}^{-3}$ and source specific emission size distributions. The primary particle emissions from road traffic were estimated from $\mathrm{NO}_{\mathrm{x}}$ emissions, using a $\mathrm{NO}_{\mathrm{x}}$ to particle number conversion factor of $3 \times 10^{14} \mathrm{~g}^{-1}$ estimated from data in Kristensson et al. (2004). Table S1 in the Supplement gives the lognormal size distribution parameters used for the road, ship and non industrial combustion emissions. The road emission size distribution was adopted from Kristensson et al. (2004). This particle number size distribution is dominated by a nucleation mode around $20 \mathrm{~nm}$ in 
diameter, which comprises approximately $90 \%$ of the particle number concentration and an accumulation mode around $80 \mathrm{~nm}$ in diameter. This type of particle number size distribution is typical for diesel fueled vehicle emissions (Kittelson et al., 2002) which are likely to be the dominating source to the submicron road particle emissions. The nucleation mode particles from diesel engines mainly consist of organic compounds from lubrication oils while the accumulation mode is dominated by non-volatile soot agglomerates coated with organic material (Kittelson et al., 2002). Hence, in this work it was estimated that the nucleation mode particles emitted from road traffic were composed purely of organic material while the emitted accumulation mode particles were composed of soot agglomerates coated with 15 mass percent organic material (POA). The ship emission size distribution was measured by Petzold et al. (2008) and the chemical composition by Moldanová et al. (2009). The nonindustrial combustion emissions were assumed to originate entirely from small scale wood combustion. The characteristic particle number size distribution for small scale wood burning emissions was taken from Kristensson (2005) and the chemical composition from Schauer et al. (2001). The emitted anthropogenic primary particle mass not composed of POA or soot was assumed to be composed of water insoluble minerals (metal oxides/hydroxides).

For Denmark and southern Sweden the anthropogenic PM2.5 and $\mathrm{NO}_{\mathrm{x}}$ emissions along the trajectories are from Danish National Environmental Research Institute (NERI) and Environmental Dept., City of Malmö (Gustafsson, 2001) respectively (see Sect. 2.3.2). For the rest of Europe the emissions were taken from the European Monitoring and Evaluation Program (EMEP) emission database, for year 2006 (Vestreng et al., 2006). The spatial resolution of the emission data was $50 \times 50 \mathrm{~km}^{2}$ for the EMEP emissions, $17 \times 17 \mathrm{~km}^{2}$ for the Danish non-road emissions and $1 \times 1 \mathrm{~km}^{2}$ for all emissions in southern Sweden and the Danish road emissions.

\subsubsection{Aerosol cloud interaction}

Clouds are included if the modeled solar irradiance at the surface is larger than the solar irradiance predicted by the HYSPLIT model (Draxler and Rolph, 2011). The altitude of the clouds is determined from the vertical relative humidity profiles along the trajectories, assuming that clouds are present if the $\mathrm{RH}>98 \%$. If this relative humidity is not reached within the lower $2000 \mathrm{~m}$ of the atmosphere (aerosol dynamics model domain), but the difference between the solar irradiance in ADCHEM (without clouds) and the solar irradiance from the HYSPLIT model still imply that clouds need to be present, the clouds are included above the aerosol dynamics model domain without contact with the modeled aerosol particles. For the case studied in this work the rainfall originated from clouds more than $2000 \mathrm{~m}$ a.g.l.
Ideally the cloud droplets number size distribution should be modeled with a dynamic cloud model, which takes into account the meteorological conditions and aerosol properties. However, this would become computationally expensive and the uncertainties concerning the meteorological conditions (e.g. updraft velocity) would make the results uncertain anyhow. For cumulus clouds the cloud droplet diameter typically increases from 7-9 $\mu \mathrm{m}$ at the cloud base to $13-$ $14 \mu \mathrm{m}$ at the top of the cloud, while for stratus clouds the cloud droplet properties are more uniform within the whole cloud, with usually a narrow droplet distribution which can be approximated with a lognormal or gamma distribution (Rogers and Yau, 1989). Hence, in this work the cloud droplet number size distribution was estimated to be lognormal distributed with a mode diameter of $10 \mu \mathrm{m}$ and a standard deviation of 1.2 for all conditions. The number of cloud droplets is determined by minimizing the difference between the modeled solar irradiance at the surface, and the solar irradiance from the HYSPLIT model e.g. if the modeled solar irradiance from ADCHEM is larger than given by the HYSPLIT model, the cloud droplet number concentration is increased in ADCHEM until the solar irradiance at the surface is equal with the value given by the HYSPLIT model.

\subsubsection{Homogeneous nucleation}

For all simulations homogeneous nucleation was included, using the kinetic nucleation theory (Eq. 4) (McMurry and Friedlander, 1979 and Kulmala et al., 2006). Stable nucleation clusters with a particle diameter of $1.5 \mathrm{~nm}\left(\mathrm{~N}_{1.5 \mathrm{~nm}}\right)$ were assumed to be formed, using a correlation coefficient $(K)$ of $3.2 \times 10^{-14} \mathrm{~s}^{-1} \mathrm{~cm}^{3}$. This value is the median value from measurements at Hohenpeissenberg in Germany (Paasonen et al., 2009).

$J_{1.5 \mathrm{~nm}}=\frac{d N_{1.5 \mathrm{~nm}}}{d t}=K\left[\mathrm{H}_{2} \mathrm{SO}_{4}\right]^{2}$

\subsubsection{Inorganic particle phase chemistry and particle water content}

The aerosol dynamics and particle phase chemistry model includes a thermodynamic model. The main purpose of the model is to calculate the saturation vapor pressures (concentrations) of hydrochloride acid, nitric acid and ammonia, and equilibrium concentrations of sulfur dioxide and hydrogen peroxide in the particle or cloud droplet water. In the model it is assumed that the inorganic aerosol particle phase is a pure aqueous solution, even if the relative humidity (RH) in the atmosphere is low. However, if the product of the saturation vapor pressure of ammonia and nitric acid and/or ammonia and hydrochloride acid is lower above a solid ammonium nitrate and/or solid ammonium chloride salt surface than above the aqueous solution, the saturation vapor pressures for ammonia, nitric acid and hydrochloride acid above 
the solid salt surface are used instead of the saturation vapor pressures above the liquid surface. This method has previously been used by e.g. Zhang and Wexler (2008).

From the modeled particle mole concentrations of ammonium, chloride, sodium, nitrate and sulfate an approximated particle salt composition is estimated for each particle size bin according to the explicit scheme in Appendix E.

Molalities of single salts $\left(m_{i}^{0}\right)$, for $\mathrm{NH}_{4} \mathrm{NO}_{3}, \mathrm{HNO}_{3}$, $\left(\mathrm{NH}_{4}\right)_{2} \mathrm{SO}_{4}, \mathrm{NH}_{4} \mathrm{HSO}_{4}, \mathrm{H}_{2} \mathrm{SO}_{4}, \mathrm{NaHSO}_{4},(\mathrm{Na})_{2} \mathrm{SO}_{4}, \mathrm{NaCl}$ and $\mathrm{HCl}$ are calculated according to the parameterizations from Table B.10 in Jacobson (2005b). These parameterizations are high order polynomials as functions of the water activity $\left(a_{w}\right)$. The water mass content $(W)$ in the inorganic particle fraction in each particle size bin is derived using the Zdanovskii-Stokes-Robinson (ZSR) model (Stokes and Robinson, 1966).

The inorganic and organic growth factor $\left(\mathrm{Gf}_{i}\right.$ and $\left.\mathrm{Gf}_{o}\right)$ are

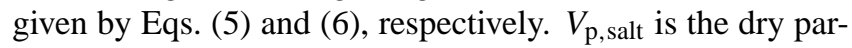
ticle volume of water soluble inorganic salts and $\rho_{\text {water }}$ is the density of water. Using Eq. (6), the organic growth factor is 1.2 when the water activity is equal to 0.9 .

$\mathrm{Gf}_{i}=\left(\frac{V_{\mathrm{p}, \text { salt }}+W / \rho_{\text {water }}}{W / \rho_{\text {water }}}\right)^{1 / 3}$

$\mathrm{Gf}_{o}=\left(1+0.081 \frac{a_{w}}{\left(1-a_{w}\right)}\right)^{1 / 3}$

Once the water content has been calculated the molalities of all ions can be determined. The mean binary solute activity coefficients of each salt in the particle water phase are calculated with the parameters in Table B.9 in Jacobson (2005b). From these binary activity coefficients the mean mixed solute activity coefficients are derived using Bromley's method (Bromley, 1973). The next step is to determine the hydrogen ion concentration in the particle water phase from the ion balance (Eq. 7).

$$
\begin{aligned}
& {\left[\mathrm{H}^{+}\right]+\left[\mathrm{NH}_{4}^{+}\right]+\left[\mathrm{Na}^{+}\right]=\left[\mathrm{NO}_{3}^{-}\right]+2\left[\mathrm{SO}_{4}^{-2}\right]} \\
& +\left[\mathrm{HSO}_{4}^{-}\right]+\left[\mathrm{Cl}^{-}\right]+\left[\mathrm{OH}^{-}\right]+\left[\mathrm{HCO}_{3}^{-}\right]+2\left[\mathrm{CO}_{3}^{-2}\right]
\end{aligned}
$$

The concentrations in Eq. (7) can be replaced with known equilibrium coefficients, activity coefficients, the partial pressure of $\mathrm{CO}_{2}$ (390 ppmv), the $\mathrm{N}(-\mathrm{III})$ concentration $\left(\left[\mathrm{NH}_{3}(\mathrm{aq})\right]+\left[\mathrm{NH}_{4}^{+}\right]\right),[\mathrm{S}(\mathrm{VI})],[\mathrm{N}(\mathrm{V})]\left(\left[\mathrm{HNO}_{3}(\mathrm{aq})\right]+\left[\mathrm{NO}_{3}^{-}\right]\right)$ and $[\mathrm{Cl}(\mathrm{I})]\left([\mathrm{HCl}(\mathrm{aq})]+\left[\mathrm{Cl}^{-}\right]\right)$. The final expression then becomes a 7th order polynomial with $\left[\mathrm{H}^{+}\right]$as the only unknown. The hydrogen ion concentration is given by the maximum real root of this polynomial.

Finally the saturation vapor pressures of ammonia, nitric acid and hydrochloride acid and the equilibrium concentrations of sulfuric acid, and hydrogen peroxide can be determined using the derived hydrogen ion concentration and the mean mixed solute activity coefficients. The saturation vapor pressures (concentrations) are used when solving the condensation/evaporation equation (Eq. 2). The growth rate due to sulfate production, from the reaction between sulfur dioxide and hydrogen peroxide in the particle water phase, is calculated using Eq. (8) (Seinfeld and Pandis, 2006).

$$
\begin{aligned}
& \frac{d[\mathrm{~S}(\mathrm{VI})]}{d t}= \\
& \frac{W k_{\mathrm{S}(\mathrm{IV})}\left[\mathrm{H}_{2} \mathrm{O}_{2}\right] \gamma_{\mathrm{H}_{2} \mathrm{O}_{2}}\left[\mathrm{HSO}_{3}^{-}\right] \gamma_{\mathrm{HSO}_{3}^{-}}\left[\mathrm{H}^{+}\right] \gamma_{\mathrm{H}^{+}}}{\left(1+K_{\mathrm{S}(\mathrm{IV})}\left[\mathrm{H}^{+}\right] \gamma_{\mathrm{H}^{+}}\right)}\left(\text {moles s}^{-1}\right)
\end{aligned}
$$

$k_{\mathrm{S}(\mathrm{IV})}$ is the irreversible reaction rate coefficient for the reaction between $\mathrm{S}(\mathrm{IV})$ and $\mathrm{H}_{2} \mathrm{O}_{2}$ in the particle water phase, $K_{\mathrm{S}(\mathrm{IV})}$ is the equilibrium coefficient of S(IV) dissolution and $\gamma_{i}$ is the activity coefficient for compound $i$.

\subsection{Gas phase model}

The chemical kinetic code included in the gas phase model is solved with MATLABs $®$ ode15s solver for stiff ordinary differential equations. This solver uses an adaptive time step length according to the specified error tolerance. Most of the reactions are taken from the kinetic code used in the model by Pirjola and Kulmala (1998) (originally from EMEP). Some new reactions, mainly concerning the oxidation of benzene, toluene and xylene are also included in the kinetic code. The reaction rates were updated for those of the reactions where new rates were found in the literature (Sander et al., 2006; Seinfeld and Pandis, 2006 and Atkinson et al., 2004). Pirjola and Kulmala (1998) included reactions involving dimethylsulfide (DMS) from the ocean in their model. These reactions were however not considered in the chemical kinetic code used in this work. All natural emission of DMS from the oceans was instead assumed to be sulfur dioxide following Simpson et al. (2003).

The photochemical reactions depend on the spectral actinic flux (photons $\mathrm{cm}^{-2} \mathrm{~s}^{-1} \mathrm{~nm}^{-1}$ ). The actinic flux is the flux of photons from all directions into a volume of air (Seinfeld and Pandis, 2006). The actinic flux $\left(F_{a}\right)$ is calculated using the radiative transfer model described in Sect. 2.5. The photolysis rates are directly proportional to the actinic flux incident on a volume of air (Cotte et al., 1997). The wavelength $(\lambda)$ dependent absorption cross sections $(\sigma)$ and quantum yields $(Q)$ for the different gases undergoing photochemical reactions were found in Sander et al. (2006). Equation (9) below gives the photochemical reaction rates for species $A$.

$j_{A}=\sum_{i} \sigma_{A}\left(\lambda_{i}, T\right) Q\left(\lambda_{i}, T\right) F_{a}\left(\lambda_{i}\right) \Delta \lambda_{i}$

\subsubsection{Dry deposition and wet deposition of gases}

As for the particles the dry deposition velocity of gases depends on an aerodynamic resistance $\left(r_{a}\right)$ and a quasi-laminar resistance $\left(r_{b}\right)$ in series. For gases the surface resistance $\left(r_{c}\right)$, is also needed. The surface resistance depends on the surface 
structure as well as the reactivity of the gas (Wesely, 1989 and Seinfeld and Pandis, 2006). The model for dry deposition velocity of gases is described in Appendix $\mathrm{F}$.

The below cloud scavenging of $\mathrm{SO}_{2}, \mathrm{HNO}_{3}, \mathrm{NH}_{3}, \mathrm{H}_{2} \mathrm{O}_{2}$ and $\mathrm{HCHO}$ are described by the parameterization used in Simpson et al. (2003). For all other gases the below cloud scavenging was assumed to be an insignificant loss mechanism.

\subsubsection{Gas phase emissions}

The gas phase chemistry model takes into account emissions of Biogenic volatile organic compounds (BVOCs) and anthropogenic VOC (AVOC) emissions, $\mathrm{CO}, \mathrm{NO}_{\mathrm{x}}$, sulfur dioxide and ammonia. The emission data of anthropogenic organic hydrocarbons are not given for each individual species but rather as total Non-Methane Volatile Organic Carbon (NMVOC) emissions. Source specific emissions of nonaromatic hydrocarbons were estimated from the NMVOC emissions, using Table 4.3 in Simpson et al. (2003). The total anthropogenic aromatic hydrocarbon emissions (by Simpson et al. (2003) considered as $O$-xylene emissions) were divided into toluene, xylene and benzene emissions according to the global emissions estimated by Henze et al. (2008). For road traffic emissions $36.7 \%$ of the NMVOC are emitted as aromatic hydrocarbons, while for most of the 9 other emission sources specified in Simpson et al. (2003), the aromatic NMVOC fraction is much smaller. According to Calvert et al. (2002) aromatic hydrocarbons contributes to ( 20-30\%) of the total VOC concentration in urban environments.

The anthropogenic gas phase emissions were adopted from EMEPs emission database for the year 2006 (Vestreng et al., 2006), except for Denmark and southern Sweden where the emissions are from Danish National Environmental Research Institute (NERI) and Environmental Dept., City of Malmö (Gustafsson, 2001) respectively. The EMEP emissions have a spatial resolution of $50 \times 50 \mathrm{~km}^{2}$, the Swedish emissions have a resolution of $1 \times 1 \mathrm{~km}^{2}$ and the Danish emissions have a resolution of $1 \times 1 \mathrm{~km}^{2}$ for road emissions and $17 \times 17 \mathrm{~km}^{2}$ for all other emission sectors. All emissions were divided into the EMEP emission sectors S1 to S11 as well as ship emissions and natural sulfur dioxide emissions. The yearly emissions were multiplied with country specific diurnal, weekly and monthly emission variation factors based on EMEP's data. The monthly variations in the natural emissions of sulfur dioxide from DMS oxidation were considered using the monthly emission variations from Tarrasón et al. (1995).

The BVOC species considered are isoprene, $\alpha$-pinene, $\beta$ pinene, $\Delta 3$-carene and D-limonene based on LPJ-GUESS' ability to assign species-specific emission capacities (e.g., Schurgers et al., 2009b and Arneth et al., 2008), and the monoterpene speciation in Steinbrecher et al. (2009). These species are oxidized by $\mathrm{OH}, \mathrm{O}_{3}$ and $\mathrm{NO}_{3}$. The products from these reactions are generally less volatile than the initial com- pounds. Some of them are therefore able to condense after one or several oxidation steps. BVOCs have a relatively short lifetime (minutes to hours) during the daytime in the troposphere (Atkinson and Arey, 2003). Due to the short lifetime of these compounds the concentrations can be considerably higher close to the ground (at the source) than at the top of the boundary layer. Both for the particle and gas phase chemistry it is important to capture the vertical concentration gradient of BVOCs. The emissions of BVOCs from the ground depend strongly on the biomass density and the vegetation species composition, but also on the canopy temperature and for some compounds and vegetation species the photosynthetic active radiation (PAR) (Guenther, 1997).

The emission of BVOCs from different species can either be described as:

1. Volatilization of stored compounds (depend only on temperature when considering short timescales).

2. VOC emissions directly reflecting VOC production (typically varying with temperature and light).

An example of the second case is the light-dependent production of isoprene in the chloroplast. Most monoterpene emissions, particularly those from conifers, are due to volatilization of stored compound (Guenther, 1997), although in recent years light-dependent emissions of non-stored monoterpenes have been found to take place in many broadleaf trees, and may also occur at least from some monoterpene chemical species in conifer (for discussion see Schurgers et al. (2009a) and references therein).

The emissions of stored and synthesized monoterpenes and isoprene were modeled using the vegetation model LPJGUESS in combination with isoprene and monoterpeneproduction linked to their chloroplastic production following Niinemets et al. (1999, 2002). Monoterpene storage and emissions from storage are described in Schurgers et al. (2009a). Short-term variations of modeled emissions display the typically observed light and temperature dependence (Arneth et al., 2007). The model's shortest time step is one day and diurnal course of emissions were calculated from the daily totals following well-established empirical functions for temperature and light-dependencies by Guenther (1997). LPJ-GUESS was applied with 17 tree species and 3 generic shrub and herb types as functional types (Schurgers et al., 2009b). Each of these was associated with an isoprene and monoterpene production potential for standard environmental conditions, implemented as a fractional contribution of photosynthetic electron-transport rate for BVOC production (Niinemets et al., 1999; Arneth et al., 2007). The simulation of tree-species rather than plant functional types allows realistic values of these production capacities to be assigned (Schurgers et al., 2009b). After a 300-year spin-up, the simulation was run for the period 1981-2006 with monthly averaged climate data for Europe from Haylock et al. (2008). For the periods 28 April to 15 October 2005 and 16 May to 
28 October 2006 the monthly data were replaced by daily observations to capture the day-to-day variability in emissions. Daily emissions with a spatial resolution of $15^{\prime} \times 15^{\prime}$ $\left(\sim 25 \times 25 \mathrm{~km}^{2}\right)$ were provided for isoprene and 17 different monoterpene species, the speciation of the monoterpenes was done following Steinbrecher et al. (2009). These emissions from natural vegetation were corrected for the presence of land use with land cover data from Ramankutty et al. (2008).

Since the kinetic code in ADCHEM only includes $\alpha$ pinene, $\beta$-pinene, $\Delta 3$-carene and $\mathrm{D}$-limonene, the emissions of all other monoterpenes were distributed among the monoterpenes included in the kinetic code, depending on their emission rates.

\subsection{Organic mass partitioning}

The secondary organic aerosol formation in ADCHEM can either be modeled with the traditional two-product model approach (Odum et al., 1996), or the recently proposed VBS approach (Donahue et al., 2006 and Robinson et al., 2007). One advantage with the two-product model used in ADCHEM is that it models the SOA formation from source specific organic compounds (e.g. oxidation products of monoterpenes, isoprene, benzene, toluene and xylene) in a computationally inexpensive way.

The VBS scheme lumps all organic species into different bins according to their volatility (given by their saturation concentration $\left(\mathrm{C}^{*}\right)$, at $298 \mathrm{~K}$ ) (Robinson et al., 2007). This method thereby generally loses the information of the chemical reactions which the individual organic compounds are involved in, but is designed to be able to predict realistic SOA formation rates found in the atmosphere using a model with relatively low complexity and only a few model parameters.

Recently, Jimenez et al. (2009) developed a 2D-VBS method which apart from classifying the organic compounds according to their volatility also includes a second dimension, oxygen to carbon ratio (O:C-ratio). This 2D-VBS method is implemented in ADCHEM, with slightly different assumptions which are described in Sects. 2.4.2 and 2.4.3.

Both the 2D-VBS model and the two-product model used in ADCHEM treat the SOA formation as a dynamic process that evolves over time, considering the oxidation agent and SOA precursor concentrations, the time of ageing (exposure time) and meteorological conditions (temperature).

One important difference between the two methods, which influences the dynamic SOA formation, is that the VBS model takes into account the fact that SOA formation generally involves several oxidation steps, while the two-product model simply assumes that it is the initial oxidation step which determines the properties of the final products. Therefore the two-product model used in ADCHEM cannot take into account the fact that more volatile compounds generally need longer time (several oxidation steps) of ageing before they are incorporated into the aerosol particle phase than less volatile compounds.

\subsubsection{SOA formation with the two-product model}

According to the two-product model developed by Odum et al. (1996) the organic mass partitioning between gas and particle phase can be parameterized as a function of the organic aerosol mass $\left(M_{o}\right)$, using two surrogate compounds with different mass based stoichiometric yields $\left(\alpha_{i}\right)$.

Equation 10 gives the mass fraction $\left(F_{i}\right)$ of the oxidation product $i$ which at equilibrium (without curvature effects) will partition into the particle phase. In combination with the Kelvin equation Eq. (10) is used to derive the particle size dependent saturation concentrations which are used in the condensation and evaporation algorithm (See Sect. 2.2.2). $K_{o m, i}$ is the partitioning coefficient of product $i$. Values of $\alpha_{i}$ and $K_{o m, i}$ from Griffin et al. (1999), Svendby et al. (2008), Henze and Seinfeld (2006) and $\mathrm{Ng}$ et al. (2007) are given in Table S2 in the Supplement, for all organic oxidation products forming secondary organic aerosol in the model. $K_{o m, 1}$ and $K_{o m, 2}$ describes the volatility of the two surrogate oxidation products which represent all the reaction products.

$F_{i}=\frac{M_{o} K_{o m, i}}{1+K_{o m, i} M_{o}}$

In total the two-product model in ADCHEM considers 40 different surrogate compounds, including 35 compounds for the monoterpene, isoprene, benzene, toluene and xylene oxidation products, two compounds for the non-oxidized intermediate volatile organic carbons (IVOCs) (see Sect. 2.4.4), two compounds for the non-oxidized POA and one nonvolatile compound for the IVOC and POA oxidation products (see Table S2). The partitioning coefficients and mass based stoichiometric yields of the two POA compounds were chosen in a way that the volatility should be comparable with what is used in the 2D-VBS (see Sect. 2.4.4).

Benzene, toluene and xylene first react with $\mathrm{OH}$ followed by a reaction either with $\mathrm{NO}$, forming products with a low and temperature dependent SOA-yield, or with $\mathrm{HO}_{2}$, which gives low-volatile products that have a high and temperature independent SOA-yield (at least for $M_{o}>10 \mu \mathrm{g} \mathrm{m}^{-3}$ ). The oxidation products from the $\mathrm{HO}_{2}$-pathway which form SOA are represented by completely non-volatile surrogate oxidation products ( $\mathrm{Ng}$ et al., 2007).

At high $\mathrm{NO}_{\mathrm{x}} / \mathrm{HO}_{2}$ ratios, which generally are the case in urban environments, most of the oxidation products react with $\mathrm{NO}$, while at remote regions the $\mathrm{HO}_{2}$-pathway dominates. Therefore, oxidation of BTX in urban environments generally gives relatively low SOA formation, while moving further away from the source the SOA formation can be considerably higher. Here it is mainly benzene, which is the least reactive of the three compounds, that is left to form SOA (Henze et al., 2008). In ADCHEM both the high- and low- $\mathrm{NO}_{\mathrm{x}}$ reaction pathways are 
considered simultaneously. The fraction reacting through the low- $\mathrm{NO}_{\mathrm{x}}$ pathway is given by Eq. (11). The reaction rate for the low- $\mathrm{NO}_{\mathrm{x}}$ pathway is given by $k_{\mathrm{RO}_{2}}+\mathrm{HO}_{2}=$ $1.4 \times 10^{-12} \exp (700 / T) \mathrm{cm}^{3}$ molecule $\mathrm{s}^{-1}$ and the reaction rate for the high- $\mathrm{NO}_{\mathrm{x}}$ pathway by $k_{\mathrm{RO}_{2}+\mathrm{NO}}=$ $2.6 \times 10^{-12} \exp (350 / T) \mathrm{cm}^{3}$ molecule $\mathrm{s}^{-1}$ (the Master Chemical Mechanism v 3.1 (http://www.chem.leeds.ac.uk/ Atmospheric/MCM/mcmproj.html)).

$f_{\text {low }-\mathrm{NO}_{\mathrm{x}}}=\frac{k_{\mathrm{RO}_{2}+\mathrm{HO}_{2}}\left[\mathrm{HO}_{2}\right]}{k_{\mathrm{RO}_{2}+\mathrm{NO}}[\mathrm{NO}]+k_{\mathrm{RO}_{2}+\mathrm{HO}_{2}}\left[\mathrm{HO}_{2}\right]}$

The values of the heat of vaporization $(\Delta \mathrm{H})$, which gives the temperature dependence of the partitioning coefficients for the two-product model oxidation products from $\alpha$-pinene, $\beta$-pinene, xylene and toluene, were obtained from Svendby et al. (2008). The temperature dependent partitioning coefficients are given by the Clausius Clapeyron relation (Eq. 10) from e.g. Sheehan and Bowman (2001). The heat of vaporization of the compounds formed from oxidation of benzene through the NO-pathway was assumed to be the same as for toluene.

$K_{\text {om }}(T)=K_{\text {om, ref }} \frac{T}{T_{\text {ref }}} \exp \left[\frac{\Delta \mathrm{H}}{R}\left(\frac{1}{T}-\frac{1}{T_{\text {ref }}}\right)\right]$

\subsubsection{SOA formation with the 2D-VBS model}

The 2D-VBS scheme used in ADCHEM classifies the organic compounds into 10 discrete volatility bins, separated by powers of 10 in $\mathrm{C}^{*}$, ranging from $10^{-2}$ to $10^{7} \mu \mathrm{g} \mathrm{m}^{-3}$ and 11 discrete O:C-ratios, separated by 0.1 , from 0 to 1 (in total $110(11 \times 10)$ bins $)$. The mass fraction $\left(F_{i}\right)$ in the particle phase in each volatility bin $i$ is given by Eq. (11) (Donahue et al., 2006) if the Kelvin effect is neglected. Together with the Kelvin equation Eq. (11) is used to derive the particle size dependent saturation concentrations which are used in the condensation and evaporation algorithm (See Sect. 2.2.2).

$F_{i}=\left(1+C_{i}^{*} / M_{o}\right)^{-1}$

For compounds with $\mathrm{C}^{*}$ equal to $1 \mu \mathrm{g} \mathrm{m}^{-3}$, Eq. (11) indicates that $50 \%$ of these compounds will be found in the particle phase and $50 \%$ in the gas phase, if the total particle organic mass content $\left(M_{o}\right)$ is equal to $1 \mu \mathrm{g} \mathrm{m}^{-3}$.

The temperature dependence of $\mathrm{C}^{*}$ is given by Eq. (10) if $K_{o m}$ is replaced with $\mathrm{C}^{*}$. The heat of vaporization is calculated with a recently proposed expression (Eq. 12) which states that the heat of vaporization can be estimated as a function of the saturation concentration (Epstein et al., 2010). $C_{300}^{*}$ in Eq. (12) is the saturation concentration at $300 \mathrm{~K}$.

$\Delta H=-11 \cdot \log _{10} C_{300}^{*}+129 \mathrm{kJmol}^{-1}$

In the 2D-VBS model used in ADCHEM the traditional SOA precursors (BTX, monterpenes and isoprene) are first allowed to react according to their species specific reaction rates, and then all oxidation products are incorporated into the 2D-VBS. The volatility and O:C-ratio distribution of these first oxidation step reaction products were calculated with the functionalization and fragmentation algorithms used in the 2D-VBS model (see Sect. 2.4.3). The saturation concentrations and O:C-ratios of these primary oxidation products range between $10^{7}$ and $10^{1} \mu \mathrm{g} \mathrm{m}^{-3}$ and 0 and 0.4 , respectively.

Jimenez et al. (2009) assumed that all organic compounds formed after the first oxidation step, react with the $\mathrm{OH}$ radical with a gas phase rate constant $\left(k_{\mathrm{OH}}\right)$ of $3 \times 10^{-11} \mathrm{~cm}^{3}$ molecules ${ }^{-1} \mathrm{~s}^{-1}$, and stated that the heterogeneous oxidation rate of organic compounds in the particle phase is at least 10 times slower. After one or a few oxidation reactions in the atmosphere the oxidation products lose their original signature and become increasingly similar in structure independent of the original molecular structure (Jimenez et al., 2009). Therefore, for all gas phase compounds in the 2D-VBS, the same $k_{\mathrm{OH}}$ equal with $3 \times 10^{-11} \mathrm{~cm}^{3}$ molecules ${ }^{-1} \mathrm{~s}^{-1}$ as proposed by Jimenez et al. (2009) was also used in ADCHEM. All gas phase compounds in each 2D-VBS bin were also assumed to be oxidized by $\mathrm{O}_{3}$ and $\mathrm{NO}_{3}$ with $k_{\mathrm{O} 3}=10^{-17} \mathrm{~cm}^{3}$ molecules ${ }^{-1} \mathrm{~s}^{-1}$ and $k_{\mathrm{NO} 3}=10^{-14} \mathrm{~cm}^{3}$ molecules ${ }^{-1} \mathrm{~s}^{-1}$ respectively, which are the approximate reaction rates for alkenes (Atkinson, 1997). The heterogeneous reactions were assumed to be insignificant compared to the gas phase reactions, and were therefore neglected.

\subsubsection{Functionalization and fragmentation of organic oxidation products}

Functionalization is the process by which oxidation reactions create new products with the same carbon number but higher O:C-ratio, while fragmentation creates products with lower carbon number and higher O:C-ratio. In the 2D-VBS model used in ADCHEM the functionalization algorithm was adapted from Jimenez et al. (2009). This algorithm assumes that all functionalization reactions are independent of the properties of the organic reactant. The formed products take-up one to three oxygen atoms, where on molar basis $29 \%$ take-up one oxygen atom, $49 \%$ two oxygen atoms and $22 \%$ three oxygen atoms. Since these oxygen atoms can attach differently to the carbon chain of the original molecule, there are also separate probability functions for the change in volatility (change of $C^{*}\left(\Delta C^{*}\right)$ ) of the products which takeup one, two or three oxygen atoms, varying from $-10^{1}$ to $-10^{7} \mu \mathrm{g} \mathrm{m}^{-3}$ (see Table 1). The change in O:C-ratio upon functionalization depends on the number of carbon atoms of the original molecule.

In the 2D-VBS the number of carbon atoms of the surrogate compounds varies between 29 for the bin $\left(C^{*}=10^{-2} \mu \mathrm{g} \mathrm{m}^{-3}\right.$, O:C-ratio=0) down to 2.3 for the bin $\left(C^{*}=10^{7} \mu \mathrm{g} \mathrm{m}^{-3}, \mathrm{O}: \mathrm{C}-\mathrm{ratio}=1\right)$. In the 2D-VBS an increase 
Table 1. Probability functions for the change in $\mathrm{C}^{*}$ when one to three oxygen atoms $(\mathrm{O})$ are added to the organic compounds in the $2 \mathrm{D}-\mathrm{VBS}$.

\begin{tabular}{ccrrrrrr}
\hline$\Delta \mathrm{C}^{*}\left(\mu \mathrm{g} \mathrm{m}^{-3}\right)$ & $-10^{1}$ & $-10^{2}$ & $-10^{3}$ & $-10^{4}$ & $-10^{5}$ & $-10^{6}$ & $-10^{7}$ \\
\hline$+1 \mathrm{O}$ & 0.30 & 0.50 & 0.20 & & & & \\
$+2 \mathrm{O}$ & & 0.19 & 0.38 & 0.32 & 0.11 & & \\
$+3 \mathrm{O}$ & & & 0.095 & 0.20 & 0.41 & 0.20 & 0.095 \\
\hline
\end{tabular}

in $\mathrm{C}^{*}$ by 10 without changing the $\mathrm{O}$ :C-ratio is achieved by removing two carbon atoms from a compound, while an addition of one oxygen molecule decreases the saturation concentration 3.75 times more than if hypothetically one carbon atom is added. These values are in fair agreement with the values given in Pankow and Asher (2008), which estimate that two extra carbon atoms increases the vapor pressure by almost 10 and depending on whether the oxygen atoms form hydroxyl-, aldehyde-, ketone or carboxylic acid- groups the vapor pressure decreases with 2-5 times more than if just adding one carbon atom.

In the 2D-VBS used in ADCHEM all oxidation reactions first follow the functionalization kernel and then a fraction $(f)$ of the formed oxidation products will fragmentize. Equivalent to Jimenez et al. (2009) it is assumed that the molecules that fragmentize have equal probability to split at any of the carbon bonds. Hence, for $\mathrm{C} 11$ molecules which fragmentize there will in average be $10 \%$ of all $\mathrm{C} 1$ to $\mathrm{C} 10$ molecules, on a molar basis. Each of the 2D-VBS bins on the right side of the original molecule (higher $C^{*}$ ) bin will therefore receive the same number of molecules, but different masses. Jimenez et al. (2009) assumed that part of the formed fragments have unchanged O:C-ratio while others increase their O:C-ratio. However, in the 2D-VBS used in ADCHEM it was simply assumed that the fragments from the oxidation products (formed from the functionalization reactions) always have the same O:C-ratio as the non-fragmentized molecule. Since the fragments first take up oxygen atoms before they fragmentize, they still always have larger O:Cratio than the original molecule (before reaction).

One large uncertainty with the VBS model approach is how to estimate the fraction $(f)$ of the oxidation reactions which cause the organic molecules to fragmentize and which fraction that functionalizes. Jimenez et al. (2009) proposed that the fraction of reactions that cause fragmentation at low- $\mathrm{NO}_{\mathrm{x}}$ conditions can be given as a function of the O:C-ratio according to Eq. (13). This equation is also used in the 2D-VBS model in ADCHEM, both for low- and high- $\mathrm{NO}_{\mathrm{x}}$ conditions.

$f=\left(\frac{O}{C}\right)^{1 / 6}$

The different SOA-yields for benzene, toluene and xylene at low- and high- $\mathrm{NO}_{\mathrm{x}}$ conditions are assumed to be caused by the first oxidation reactions, which are considered before the compounds enter the 2D-VBS. To account for the different yields, the benzene, toluene and xylene molecules reacting through the high- $\mathrm{NO}_{\mathrm{x}}$ pathway are always assumed to be fragmentized when they are oxidized, while those reacting through the low- $\mathrm{NO}_{\mathrm{x}}$ pathway are always functionalized. The monoterpenes and isoprene always follows the low- $\mathrm{NO}_{\mathrm{x}}$ pathway, independent of the $\mathrm{NO}$ and $\mathrm{HO}_{2}$ concentrations.

Figure S1 in the Supplement compares the modeled yields with the two-product model parameterization of the measured BTX yields from $\mathrm{Ng}$ et al. (2007). For typical atmospheric particle organic mass concentrations $\left(1-10 \mu \mathrm{g} \mathrm{m}^{-3}\right)$ the BTX yields modeled with the 2D-VBS is about $4-11 \%$ for high- $\mathrm{NO}_{\mathrm{x}}$ conditions, while $15-35 \%$ for low- $\mathrm{NO}_{\mathrm{x}}$ conditions, at $300 \mathrm{~K}$. This can be compared with the two-product model SOA yields of 5-15\% for benzene, 2-8\% for toluene and $1-4 \%$ for xylene at high- $\mathrm{NO}_{\mathrm{x}}$ conditions and $37 \%$ for benzene, $36 \%$ for toluene and $30 \%$ for xylene at low- $\mathrm{NO}_{\mathrm{x}}$ conditions.

\subsubsection{POA volatility and IVOC emissions}

Another key uncertainty with the modeled organic aerosol formation in urban environments is the volatility of the organic emissions traditionally considered to be POA (Shrivastava et al., 2008 and Tsimpidi et al., 2010). Shrivastava et al. (2008) used the 3D-CTM model PMCAMx to model the organic aerosol in the US by either treating these traditional POA emissions as non-volatile $\left(\mathrm{C}^{*}=0\right)$ or as semivolatile $\left(\mathrm{C}^{*}\right.$ between $10^{-2}$ and $10^{4} \mu \mathrm{g} \mathrm{m}^{-3}$ ). Their results illustrate that condensation of oxidized organic compounds formed from compounds which first evaporate after dilution and then are oxidized in the atmosphere, has the potential to significantly increase the summertime organic aerosol (OA) in urban environments in the USA. In this work the traditional POA emissions were treated either as non-volatile compounds $\left(\mathrm{C}^{*}=0 \mu \mathrm{g} \mathrm{m}^{-3}\right)$ or as semi-volatile. These semivolatile POA (SVPOA) mass emissions were divided into different $C^{*}$ channels according to the work by Robinson et al. (2007), Shrivastava et al. (2008) and Tsimpidi et al. (2010). Analogous with Robinson et al. (2007), Shrivastava et al. (2008) and Tsimpidi et al. (2010) the intermediate volatile organic carbon (IVOC) emissions ( $C^{*}$ between $10^{4}$ and $10^{6} \mu \mathrm{g} \mathrm{m}^{-3}$ ), were assumed to be proportional and 1.5 times larger than the POA emissions (see Table S3 in the Supplement). 
Recently performed chamber measurements on wood smoke and diesel car POA emissions indicate that the POA may evaporate slowly before reaching an equilibrium with the gas phase (at least $1 \mathrm{~h}$ ) (Grieshop et al., 2009). The spatial and temporal resolution used in ADCHEM enables the treatment of this mass transfer limited evaporation. Therefore all POA emissions in ADCHEM are initially placed in the particle phase, although they at equilibrium to a large fraction will be found in the gas phase. This enables ADCHEM to study the diffusion-limited evaporation of the SVPOA downwind of the source region, followed by the oxidation of the SVPOA in the gas phase and finally the re-condensation of the oxidized SVPOA several hours after the initial emissions.

\subsection{Radiative transfer model}

The radiative transfer model is mainly used to calculate the photolysis rate coefficients for the gas phase chemistry model and to estimate the presence of clouds. The radiative transfer model uses the quadrature two-stream approximation scheme, where the radiative fluxes are described with an upward and downward flux component. The phase function and the angular integral of the intensity field are approximated using the asymmetry parameter $(g)$ and single scattering albedo $\left(w_{0}\right)$. The model can be used to calculate the radiative transfer in a vertically inhomogeneous atmosphere with clouds and aerosols (Toon et al., 1989). The asymmetry parameter and single scattering albedo for aerosol particles and cloud droplets are calculated using a Mie-theory model. The radiative transfer model is described more in detail in Appendix G.

\section{Methods for urban plume studies}

In this section the methods used when modeling the properties of the aerosol particles inside the urban plume from Malmö are described briefly. For a more detailed description of these methods, see Roldin et al. (2011). The model is applied here for one case study, to test the model performance and to illustrate the spatial and temporal variability of the aerosol properties within the urban plume from Malmö.

\subsection{Measurements}

Particle and/or gas concentrations measured at three different stations in Sweden were either used to validate the model performance or as input to the model. The first station is an urban background station positioned in Malmö $\left(55^{\circ} 36^{\prime} \mathrm{N}\right.$, $13^{\circ} 00^{\prime} \mathrm{E}, 30 \mathrm{~m}$ a.s.l.), the second station is the EMEP background station at Vavihill $\left(56^{\circ} 01^{\prime} \mathrm{N}, 13^{\circ} 09^{\prime} \mathrm{E}, 172 \mathrm{~m}\right.$ a.s.l. $)$, about $50 \mathrm{~km}$ north from Malmö, and the third station is the EMEP background station at Aspvreten $\left(17^{\circ} 23^{\prime} \mathrm{N}, 58^{\circ} 48^{\prime} \mathrm{E}\right.$, $20 \mathrm{~m}$ a.s.l.), about $450 \mathrm{~km}$ north-east from Malmö. Descriptions of the measurement stations at Vavihill and Aspvreten can be found in Kristensson et al. (2008) and Tunved et al. (2004), respectively.

The selected case study in this article is from the 21 June 2006. Figure 3 displays the selected air mass trajectory for this case. The trajectory was derived with the HYSPLIT model (Draxler and Rolph, 2011). It arrives at $100 \mathrm{~m}$ a.g.l. in Malmö, at 6 a.m. and passes over Vavihill background station around $9 \mathrm{a} . \mathrm{m}$. The trajectory starts over England, $48 \mathrm{~h}$ upwind of Malmö and end $24 \mathrm{~h}$ downwind of Malmö close to Stockholm. Locations A, B and C in Fig. 3 are Malmö, Vavihill and Aspvreten respectively. The trajectory does not pass over Aspvreten, but about $50 \mathrm{~km}$ east from the station. Therefore it is unlikely that the urban emissions in Malmö influenced Aspvreten this time of the day. Still the measured ozone level at Aspvreten was used to check if the magnitude of the modeled ozone concentration was reasonable, with the assumption that the background ozone level is relatively uniform over large regional areas.

The particle number size distributions in Malmö and Vavihill were measured with a Scanning Mobility Particle Sizer (SMPS) and a Twin Differential Mobility Particle Sizer (TDMPS). The SMPS system in Malmö measured the urban background particle number size distribution from 10 to $660 \mathrm{~nm}$ at a roof top station about $20 \mathrm{~m}$ a.g.l., at the town hall in the north-west part downtown Malmö. During southerly air masses this station detects most of the particle emissions from Malmö. A description of the SMPS system in Malmö can be found in Roldin et al. (2011).

The TDMPS system at Vavihill field station measures the rural background particle number size distribution from 3 to $900 \mathrm{~nm}$ every $10 \mathrm{~min}$. A detailed description of the TDMPS at Vavihill can be found in Kristensson et al. (2008).

Measured concentrations of $\mathrm{NO}, \mathrm{NO}_{2}, \mathrm{O}_{3}$ and $\mathrm{SO}_{2}$ at the urban background station in Malmö and $\mathrm{O}_{3}$ at Vavihill were compared with the modeled gas phase concentrations along the trajectory (for more information about the gas phase measurements see Roldin et al., 2011).

Apart from measured particle and gas concentrations, wind direction measurements from a meteorological mast in Malmö were used to verify that the urban plume from Malmö was directed toward Vavihill. The wind direction was measured at $24 \mathrm{~m}$ a.g.l.

\subsection{Model input}

Vertical temperature and relative humidity profiles, wind speed at two altitudes within the surface layer, rainfall intensity, mixing height and emissions of isoprene, monoterpenes, anthropogenic NMVOCs, $\mathrm{NO}_{\mathrm{x}}, \mathrm{SO}_{2}, \mathrm{CO}, \mathrm{NH}_{3}$ and PM2.5 were included along the trajectories.

The meteorological data from the Global Data Assimilation System (GDAS) were downloaded from NOAA Air Resource Laboratory Real-time Environmental Application and Display sYstem (READY) (Rolph, 2011). The rainfall intensity and mixing height data along the trajectory have a spatial 


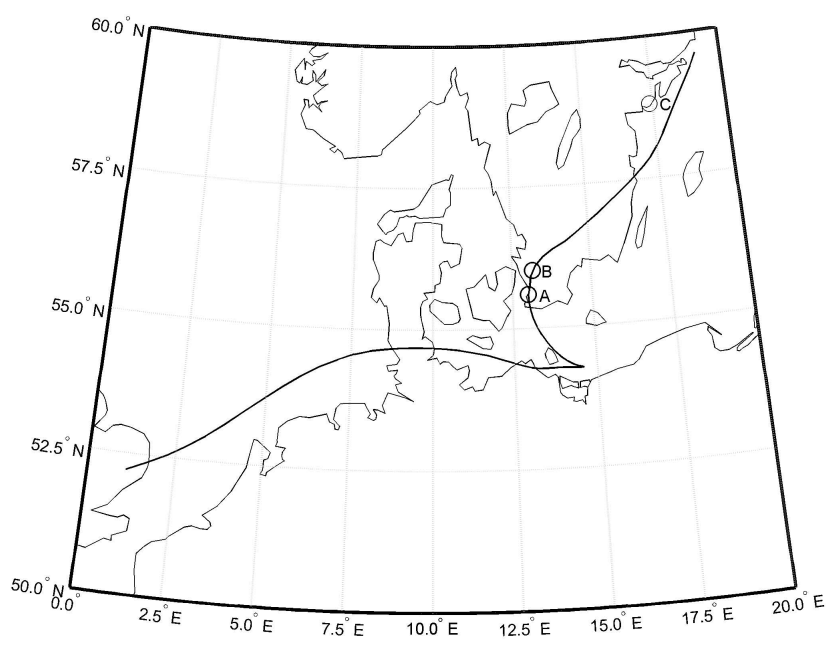

Fig. 3. Map with the air mass trajectory from the HYSPLIT model which was used when the urban plume from Malmö was modeled. The trajectory starts over England $48 \mathrm{~h}$ upwind of Malmö. It arrives in Malmö 100 ma.g.l. on the 21 June 2006, at 6 a.m. Downwind of Malmö (A) the trajectory moves northward over Sweden. About $3 \mathrm{~h}$ downwind of Malmö the trajectory reach Vavihill $(\mathbf{B})$ and $18 \mathrm{~h}$ downwind of Malmö it passes near the background station Aspvreten (C).

resolution of $1 \mathrm{~h}$ and for every three hours, vertical temperature, wind speed and relative humidity profiles were received. The vertical temperature and relative humidity data were linearly interpolated to the fixed vertical grid and the temporal resolution, which were used for the simulations. Figure S2 in the Supplement shows the vertical temperature and relative humidity profiles over Malmö and at 6 and $24 \mathrm{~h}$ downwind of Malmö. The meteorological conditions were assumed to be uniform in the horizontal direction perpendicular to the air mass trajectory. The kinematic heat flux is estimated from the horizontal wind speed gradient and potential temperature gradient within the surface layer. The kinematic heat flux is used to calculate the Monin-Obukov length which is applied when deriving the vertical and horizontal eddy diffusivity profiles and the dry deposition velocity.

The initial particle number size distributions in ADCHEM were estimated from the measured background particle number size distribution at Vavihill, according to the method described in Roldin et al. (2011). Initially ( $48 \mathrm{~h}$ upwind of Malmö) the PM2.5 mass fractions of each compound were estimated to be: 0.35 organic material, 0.03 soot, 0.26 sulfate, 0.07 nitrate, 0.12 ammonium and 0.17 minerals (metal oxides/hydroxides) below $1000 \mathrm{~m}$ a.g.l. and then changing linearly to the top of the model domain (2000 m a.g.l.), to 0.23 organic material, 0.02 soot, 0.36 sulfate, 0.11 nitrate, 0.17 ammonium and 0.11 minerals. These values are in reasonable agreement with the measured chemical composition at several European sites (Jimenez et al., 2009). The sodium and chloride concentrations were initially set to zero. Be- cause the model is only initiated $48 \mathrm{~h}$ upwind of Malmö, these initial particle properties may influence the particle composition within the urban plume from Malmö, especially for the particles larger than $\sim 1 \mu \mathrm{m}$, which have a long lifetime and relatively small sources.

\subsection{Spin-up time upwind of Malmö}

The total run time of the simulations was 3 days, starting 2 days upwind of Malmö and continuing 1 day downwind of Malmö. The first two days were used to initialize the particle and gas phase chemistry. During these days the particle number size distribution was kept fixed, while everything else were allowed to change. Once the trajectory reached the southern border of Malmö, the estimated local road emission contribution from the particle number size distribution measurements in Malmö, were included according to the method described in Roldin et al. (2011). With this method the modeled particle number size distribution at the measurement station in Malmö become comparable with the measured particle number size distribution at that time. Downwind of the urban background station in Malmö, the particle number size distribution was allowed to change due to the aerosol dynamic processes, and vertical and horizontal mixing.

\section{Results and discussion}

Results from 23 separate model simulations will be compared and discussed. The simulations were designed to study the influence of: (1) the number of size bins, (2) the size structure methods, (3) aerosol dynamic processes, (4) coupled or uncoupled condensation, (5) the VBS or traditional two-product model for secondary aerosol formation, (6) POA as semi-volatile (SVPOA) or non-volatile, (7) intermediate volatile organic carbon (IVOC) emissions with $\mathrm{C}^{*}$ between $10^{4}-10^{6} \quad \mu \mathrm{g} \mathrm{m}^{-3}$, (8) the SOA formation from BVOC emissions, (9) the SOA formation from BTX emissions, (10) the influence from all anthropogenic gas phase emissions from Malmö and (11) horizontal and vertical mixing. The model runs are listed below. If not otherwise specified the fullstationary structure with 100 size bins between 1.5 and $2500 \mathrm{~nm}$ in diameter was used, the condensation/evaporation was solved as an uncoupled process, both vertical and horizontal mixing was considered, the 2D-VBS method was used for the partitioning of organic compounds between gas and particle phase, POA was assumed to be semi-volatile and IVOC emissions were considered.

\section{All processes included (base case)}

2. Full-stationary structure with 50 size bins

3. Full-stationary structure with 25 size bins

4. Moving-center structure with 25 size bins

5. Moving-center structure with 10 size bins 
6. Combination of full-stationary and moving-center structure with 25 size bins

7. Coupled condensation

8. Two-product model

9. No aerosol dynamic processes

10. No dry deposition

11. No coagulation

12. No condensation

13. No wet deposition

14. No homogeneous nucleation

15. Doubled mixing height.

16. Doubled horizontal turbulent diffusivity

17. 1D model (without horizontal mixing)

18. Non-volatile POA (NVPOA)

19. No IVOC emissions in and downwind of Malmö

20. No BVOC emissions in and downwind of Malmö

21. No anthropogenic gas phase emissions over Malmö (no $\mathrm{NO}_{\mathrm{x}}, \mathrm{SO}_{2}, \mathrm{NMVOCs}$ and IVOCs emissions)

22. No BTX emissions in and downwind of Malmö

23. Unity mass accommodation coefficients

\subsection{Physical particle properties}

In Fig. 4a-b the modeled particle number size distributions at Vavihill ( $3 \mathrm{~h}$ downwind of Malmö) and $24 \mathrm{~h}$ downwind of Malmö, for different number of size bins and size structure methods, are compared. Given is also the measured particle number size distribution at Vavihill, at the time of arrival of the air mass trajectory. The results are from the center of the urban plume at the surface. At Vavihill (Fig. 4a) all simulations are in good agreement with each other and the measured particle number size distribution. This illustrates that for short time scales (a few hours) the model results are fairly insensitive of the number of size bins and which size structure method that is used, especially if the condensation or evaporation rates are small. $24 \mathrm{~h}$ downwind of Malmö (Fig. 4b) the difference between the simulations becomes more evident. This is especially the case for the movingcenter method and the full-stationary method when using 25 size bins. For the full-stationary method with 25 size bins, the numerical diffusion significantly broadens the size distribution (see Sect. 2.2.1). With the moving-center method errors can appear when particles from the lower size bins are averaged with the particles in higher size bins, which
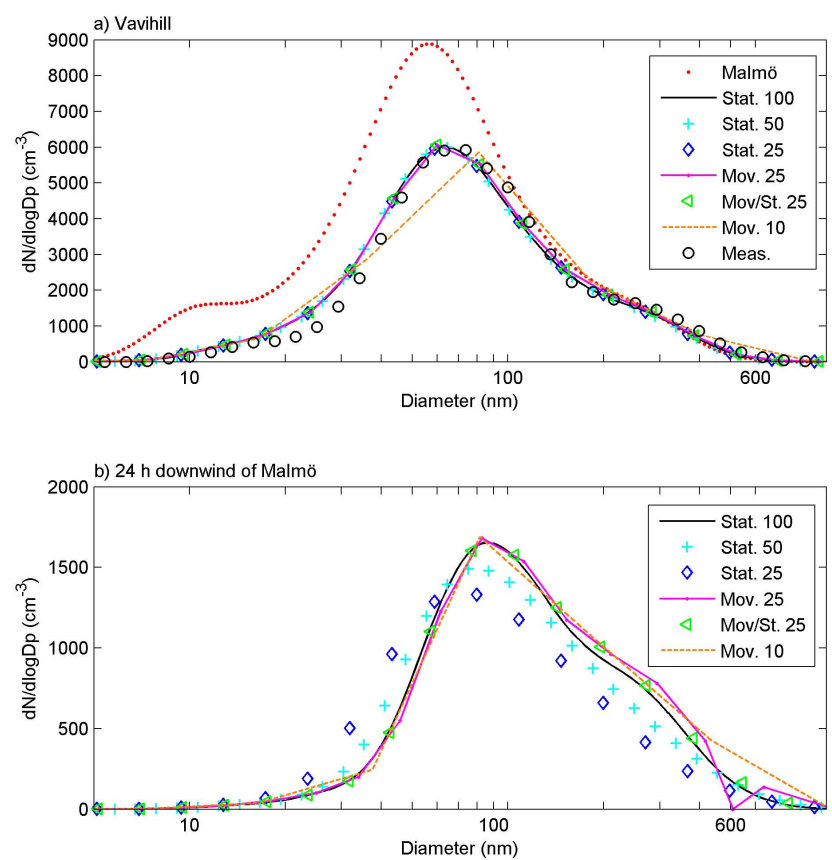

Fig. 4. Modeled particle number size distributions in the center of the urban plume at Vavihill (a) and $24 \mathrm{~h}$ downwind of Malmö (b), using different size structure methods. The results are from the simulations with the full-stationary structure using 100,50 or 25 size bins, moving-center structure with 25 or 10 size bins and a combination of the moving-center method and full-stationary method using 25 size bins (Mov/St). Panel (a) also displays the modeled (fitted) particle number size distribution at the measurement station in Malmö and the measured particle number size distribution at Vavihill.

causes some bins to get too low concentrations (zero concentration) while bordering size bins get too high concentrations. In Fig. $4 \mathrm{~b}$ this can be seen around $600 \mathrm{~nm}$ in diameter. For the moving-center method this problem is solved by decreasing the number of size bins, while for the fullstationary method the accuracy increases with the number of size bins. Figure $4 \mathrm{a}-\mathrm{b}$ also shows the result from one simulation with 25 size bins, where the moving-center method was used except once every 360th time step $(6 \mathrm{~h})$ when the full-stationary method was used. This combination of the two methods gave much smaller numerical diffusion than the full-stationary method and still eliminated the problems seen with the moving-center method.

Figure 5a-b compares the modeled particle number size distributions with or without different aerosol dynamic processes at Vavihill and $24 \mathrm{~h}$ downwind of Malmö. The result without wet deposition is only given at $24 \mathrm{~h}$ downwind of Malmö since no rainfall affected the size distribution between Malmö and Vavihill. About $2 \mathrm{~h}$ downwind of Vavihill a light rainfall $\left(\sim 0.5 \mathrm{~mm} \mathrm{~h}^{-1}\right)$ started and continued for a few hours, which affect the size distribution $24 \mathrm{~h}$ downwind of Malmö. The rainfall intensity was assumed to be constant within the whole model domain. 

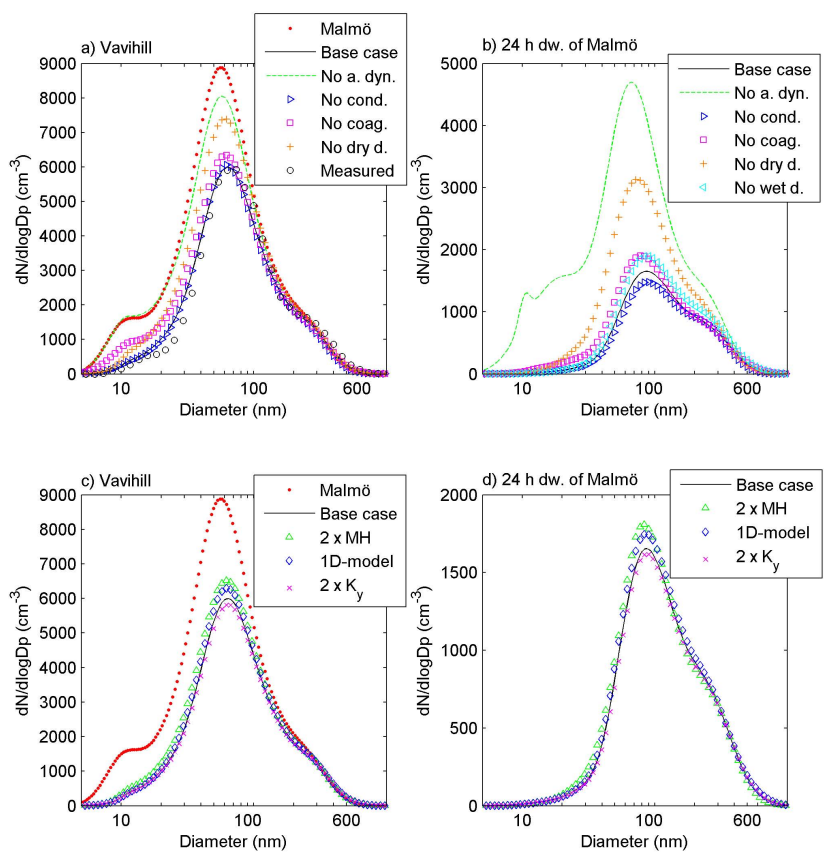

Fig. 5. Modeled particle number size distributions in the center of the urban plume at Vavihill (a and c) and $24 \mathrm{~h}$ downwind of Malmö (b and d), without different aerosol dynamic processes (a and b) and changed vertical or horizontal mixing (c and d). Panels (a) and (b) give the results from the simulations with all aerosol dynamic processes included (base case), no aerosol dynamic processes, no condensation, no coagulation, no dry deposition and no wet deposition (only in b)). Panels (c) and (d) display the results from the base case simulation, doubled mixing height $(\mathrm{MH})$, no horizontal mixing (1D-model) and doubled horizontal mixing $\left(2 \times \mathrm{K}_{y}\right)$. In (a) the modeled (fitted) particle number size distribution at the measurement station in Malmö and the measured particle number size distribution at Vavihill is also illustrated.

The aerosol dynamic processes with largest influence on the particle number concentration both at Vavihill and $24 \mathrm{~h}$ downwind of Malmö was dry deposition. The reason for this is mainly the relatively few nucleation mode particles. Condensation and evaporation had little influence on the results at Vavihill but larger influence on the size distribution $24 \mathrm{~h}$ downwind of Malmö. Using unity mass accommodation coefficients for all condensable compounds instead of the values given in Sect. 2.2.2 had negligible impact on the modeled particle number size distribution and chemical composition (not shown). The primary particle emissions between Malmö and Vavihill had a marginal impact on the size distribution below $30 \mathrm{~nm}$ which can be seen when comparing the initial particle number size distribution and the results without aerosol dynamic processes.

When not considering aerosol dynamic processes the size distribution was almost preserved between Malmö and Vavihill. This illustrates that on short time scales, vertical and horizontal mixing had little influence on the model results in the center of the urban plume. For the vertical mixing, this is mainly due to the low and constant boundary layer height at $300 \mathrm{~m}$ between Malmö and Vavihill. An increasing mixing height effectively dilutes the boundary layer. This explains why the number concentration is significantly lower $24 \mathrm{~h}$ downwind of Malmö than in the city, even without any aerosol dynamic processes.

The homogeneous nucleation downwind of Malmö had a marginal impact on the modeled particle number size distribution above $5 \mathrm{~nm}$ in diameter, within $24 \mathrm{~h}$ downwind of Malmö (not shown). The main reason for this was probably not the formation rate $\left(\mathrm{J}_{1.5 \mathrm{~nm}}\right)$ which reached a maximum of about $1 \mathrm{~s}^{-1}$ within the boundary layer during the afternoon. Instead the limiting factors were likely the diameter growth rate of the smallest particles and the relatively large coagulation sink. The growth rate of the smallest particles is determined by the concentrations of low-volatile compounds (e.g. $\mathrm{H}_{2} \mathrm{SO}_{4}$ and some organic compounds). Unfortunately the amount and origin of the low-volatile organic compounds which can contribute to the initial growth of these particles are not well known. Therefore it is not possible to dismiss the possibility that the model significantly underestimated the growth rate of the particles below $5 \mathrm{~nm}$ in diameter.

Figure $5 \mathrm{c}-\mathrm{d}$ illustrate the modeled particle number size distributions at Vavihill and $24 \mathrm{~h}$ downwind of Malmö from the simulations with doubled mixing height $(\mathrm{MH})$, no horizontal mixing (1-D model) and doubled horizontal eddy diffusivity $\left(2 \times \mathrm{K}_{y}\right)$. When doubling the mixing height the particle number concentration became slightly higher. This is mainly due to the decreasing influence of dry deposition. It is important to mention that the initial particle number size distribution in Malmö within the whole boundary layer was assumed to be the same for both mixing heights.

Figure 6 shows the modeled particle number concentration $(\mathrm{PN})$ within the whole 2-dimentional model domain $(2 \mathrm{~km} \times 20 \mathrm{~km})$ at different distances (times) downwind of Malmö. At Vavihill (Fig. 6a) the concentration difference between the background and the urban plume is still distinct both in the vertical and horizontal direction. The explanation to this is that the atmospheric stability prevented large horizontal dispersion and the mixing height in the model was fixed at $300 \mathrm{~m}$ a.g.1. between Malmö and Vavihill, which prevented significant vertical dilution. Downwind of Vavihill (between 10 a.m. and 12 a.m.) the mixing height in the model rose to $1000 \mathrm{~m}$ which effectively diluted the boundary layer. During the evening (4 p.m. until 9 p.m.) the mixing height decreased to $300 \mathrm{~m}$ and a stable residual layer was created. The residual layer can be distinguished $12 \mathrm{~h}$ downwind of Malmö as a horizontal streak with higher particle number concentrations between 700 and $1000 \mathrm{~m}$ a.g.l. (Fig. 6b). This concentration difference was even more pronounced $24 \mathrm{~h}$ downwind of Malmö (Fig. 6c). The increasing concentration difference between the boundary layer and the residual layer was caused by the dry deposition losses in the well mixed boundary layer. $24 \mathrm{~h}$ downwind of Malmö, when 

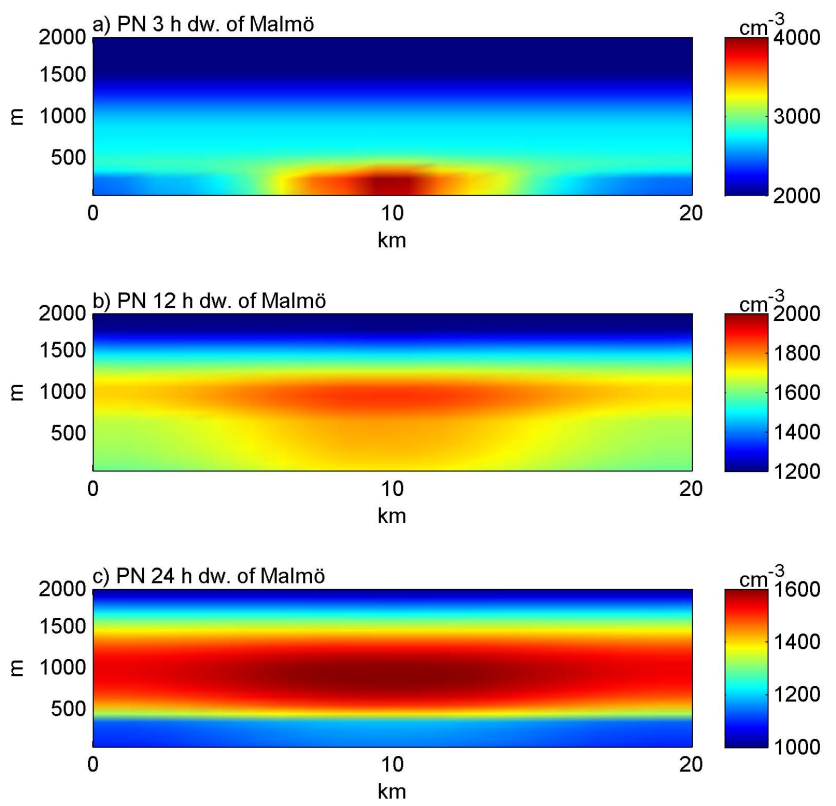

Fig. 6. Modeled total particle number concentration (PN) (a) $3 \mathrm{~h}$ downwind of Malmö, (b) $12 \mathrm{~h}$ downwind of Malmö and (c) $24 \mathrm{~h}$ downwind of Malmö, in the whole model domain $(20 \mathrm{~km}$ in the horizontal and $2 \mathrm{~km}$ in the vertical direction) perpendicular to the air mass trajectory. Vavihill (VVHL) is position in the center of the horizontal model domain $3 \mathrm{~h}$ downwind of Malmö.

parts of the residual layer had been separated from the surface for up to $12 \mathrm{~h}$, the concentration gradient between the boundary layer $(0-300 \mathrm{~m})$ and residual layer $(300-1000 \mathrm{~m})$ was much larger than the concentration gradient between the center of the urban plume and the horizontal boundaries (Fig. 6c).

\subsection{Chemical gas and particle phase properties}

All the measured gases $\left(\mathrm{NO}, \mathrm{NO}_{2}, \mathrm{O}_{3}\right.$ and $\left.\mathrm{SO}_{2}\right)$ were well captured by the model in Malmö, when considering the anthropogenic gas phase emissions in the city (Fig. 7). Unfortunately $\mathrm{O}_{3}$ was the only gas phase compound that was measured with high time resolution at Vavihill and Aspvreten. The modeled $\mathrm{O}_{3}$ concentration agrees very well with the measured concentrations at Malmö. At Vavihill and Aspvreten the model seems to overestimate the $\mathrm{O}_{3}$ concentration with $10-20 \%$.

The modeled PM2.5 mass of ammonium, nitrate, sulfate, organic material and soot, from one hours upwind of Malmö until $24 \mathrm{~h}$ downwind of Malmö are given in Fig. 8a. At Malmö there was a significant increase in the soot mass and to a smaller extent the organic mass because of the primary particle emissions in the city. This primary particle mass increase is constrained by the measurements at the urban background station in Malmö (see Sect. 3.3). The soot particle mass emitted in Malmö was primarily lost by dry deposition
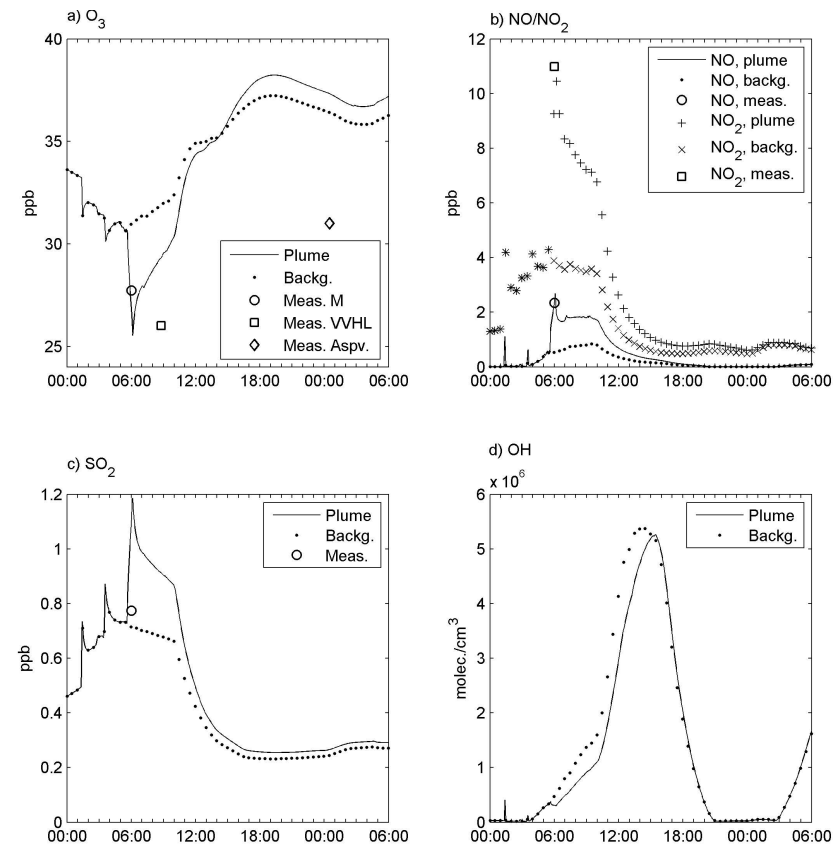

Fig. 7. Modeled concentrations of (a) $\mathrm{O}_{3}$, (b) $\mathrm{NO}$ and $\mathrm{NO}_{2}$, (c) $\mathrm{SO}_{2}$ and (d) $\mathrm{OH}$ at the surface, from $6 \mathrm{~h}$ upwind of Malmö (00:00) to $24 \mathrm{~h}$ downwind of Malmö (06:00), in the center of the urban plume and outside the urban plume. Given are also the measured $\mathrm{O}_{3}$ concentrations in Malmö, at Vavihill and at Aspvreten, and the measured $\mathrm{NO}, \mathrm{NO}_{2}$ and $\mathrm{SO}_{2}$ concentrations in Malmö.

between Malmö ( 6 a.m.) and 10 a.m. After this the mixing height rose steeply, which effectively diluted the boundary layer (see e.g. Fig. 10e).

A large fraction of the organic particle mass consists of semi-volatile compounds which can be transported to or from the particle phase when the temperature or concentrations changes (see Fig. 12). Still, the modeled organic PM2.5 mass shows no visible correlation with the semi-volatile ammonium nitrate content. The reason for this is that it was the relative humidity and not the temperature fluctuations which mainly were responsible for the large changes in the PM2.5 ammonium nitrate content. In the model all organic compounds were assumed to be water insoluble and therefore the organic particle mass was not directly affected by the relative humidity. When considering coupled condensation, the particle nitrate content was smaller while the ammonium content was about the same as for the uncoupled condensation simulations. The reason for this is that the particles were not fully neutralized with the uncoupled condensation simulations (between 50 and $20 \%$ of the sulfate was in the form of bisulfate $\left(\mathrm{HSO}_{4}^{-}\right)$and the rest $\mathrm{SO}_{4}^{-2}$, with least neutralized particles $24 \mathrm{~h}$ downwind of Malmö).

Figure $8 \mathrm{~b}-\mathrm{c}$ illustrates the modeled mass size distributions of the major particle compounds. Noticeable is that the nitrate content is shifted toward larger particle sizes when using uncoupled condensation while the organic mass is mainly 


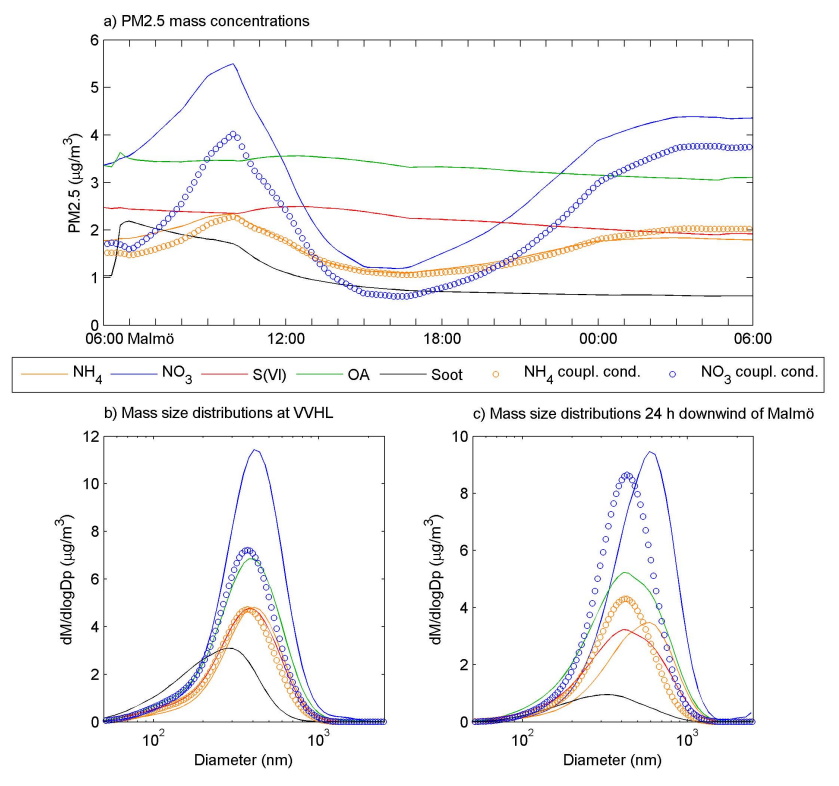

Fig. 8. (a) Modeled PM2.5 ammonium, nitrate, sulfate, organic aerosol (OA) and soot masses from $1 \mathrm{~h}$ upwind of Malmö (05:00) until $24 \mathrm{~h}$ downwind of Malmö. For ammonium and nitrate results are shown both from the uncoupled and coupled condensation simulations. Panels (b) and (c) gives the modeled particle mass size distributions of the different compounds at Vavihill and $24 \mathrm{~h}$ downwind of Malmö.

found on smaller particles. This is especially pronounced $24 \mathrm{~h}$ downwind of Malmö. Similar separation of particulate nitrate and organic material on different particle sizes are commonly observed with aerosol mass spectrometer (AMS) at Vavihill (Roldin et al., 2011). The reasons for this will be discussed below.

Figure 9 gives the size resolved mass fractions of ammonium, nitrate, sulfate, sodium, soot and organic material and the $\mathrm{pH}$, in each size bin, from the base case simulation. Ammonium and nitrate were well correlated above $100 \mathrm{~nm}$ in diameter and cycle between the accumulation mode and the gas phase, mainly driven by the relative humidity fluctuations. Downwind of Malmö the sulfate was mainly found in the Aitken and accumulation mode while the organic material dominated in the nucleation and Aitken mode, comprising between 50 and $90 \%$ of the total mass below $50 \mathrm{~nm}$ in diameter, except in and near Malmö where the Aitken mode particles mainly were composed of soot. The $\mathrm{pH}$ of the aerosol particle water content varied with the size of the particles, from about 1 in the nucleation mode to 2.5 in the coarse mode. These $\mathrm{pH}$-values can be compared with the $\mathrm{pH}$ of fully neutralized water of 5.6 (at 380 ppmv $\mathrm{CO}_{2}$ ). The main reason why the $\mathrm{pH}$ increases with the particle size is that the condensation growth rate of sulfuric acid is independent of the $\mathrm{pH}$ and the relative molar condensation growth rate is proportional to the Fuchs-Sutugin-corrected aerosol surface area (approximately proportional to the particle di- ameter) and not to the particle volume. Since the diameter to volume ratio increases with decreasing particle size, the sulfate concentration in the particle water phase decreases with increasing particle diameter. The lower hydrogen ion concentration in the larger particles explains why the nitrate was shifter toward larger particles when using uncoupled condensation but not when using coupled condensation (no $\mathrm{pH}$ dependence).

Figure 10 gives the modeled vertical PM2.5 mass profiles of different chemical compounds, in the center of the model domain, $6 \mathrm{~h}$ upwind of Malmö until $24 \mathrm{~h}$ downwind of Malmö. The mixing height is also illustrated. As a complement to Fig. 10, Fig. S4 in the Supplement shows the gas phase concentrations of ammonia, nitric acid, sulfuric acid and $\mathrm{NO}_{\mathrm{x}}$ in the vertical direction. The PM2.5 nitrate and ammonium masses have a maximum 4 to $6 \mathrm{~h}$ downwind of Malmö in the whole boundary layer, caused by the high relative humidity at that time $(\sim 90 \%)$. In contrast, the gas phase ammonia and nitric acid show a different pattern with maximum concentrations upwind of Malmö. The PM2.5 sulfate content was larger above the boundary layer over Malmö than in the boundary layer. The organic PM2.5 mass was highest near the ground and up to about $1200 \mathrm{~m}$ which was approximately the maximum altitude of the boundary layer upwind and downwind of Malmö. The soot mass increased quickly over Malmö within the boundary layer but was effectively diluted when the mixing height rose steeply around 10 a.m. As expected the $\mathrm{NO}_{\mathrm{x}}$ concentration (Fig. S4d) is well correlated with the soot particle mass. The reason for this is that both compounds mainly originate from the diesel fueled vehicle emissions in Malmö.

\subsubsection{Organic particle content}

Figure 11 displays the PM2.5 organic mass difference between the base case simulation and the following case studies: (1) without anthropogenic gas phase emissions in Malmö, (2) without BTX emissions in and downwind of Malmö, (3) without IVOC emissions in and downwind of Malmö, (4) no BVOC emissions in and downwind of Malmö, (5) Non-volatile POA (NVPOA) instead of SVPOA and (6) the two-product model instead of the 2D-VBS.

As a result of the lower $\mathrm{OH}$ concentration and higher $\mathrm{NO}$ concentration induced by the anthropogenic gas phase emissions in Malmö (see Fig. 7), the modeled organic PM2.5 mass becomes larger without anthropogenic gas phase emissions in Malmö for the first $10 \mathrm{~h}$ downwind of Malmö. However, more than $10 \mathrm{~h}$ downwind of the city the organic PM2.5 mass becomes slightly higher for the base case.

As expected the simulations without BTX, IVOC or BVOC emissions, all give lower organic mass than the base case simulation. One major difference between the BTX and the IVOCs is that the IVOCs generally only need to be oxidized one or two steps, while BTX need at least two oxidation steps, before they are low-volatile enough to form 

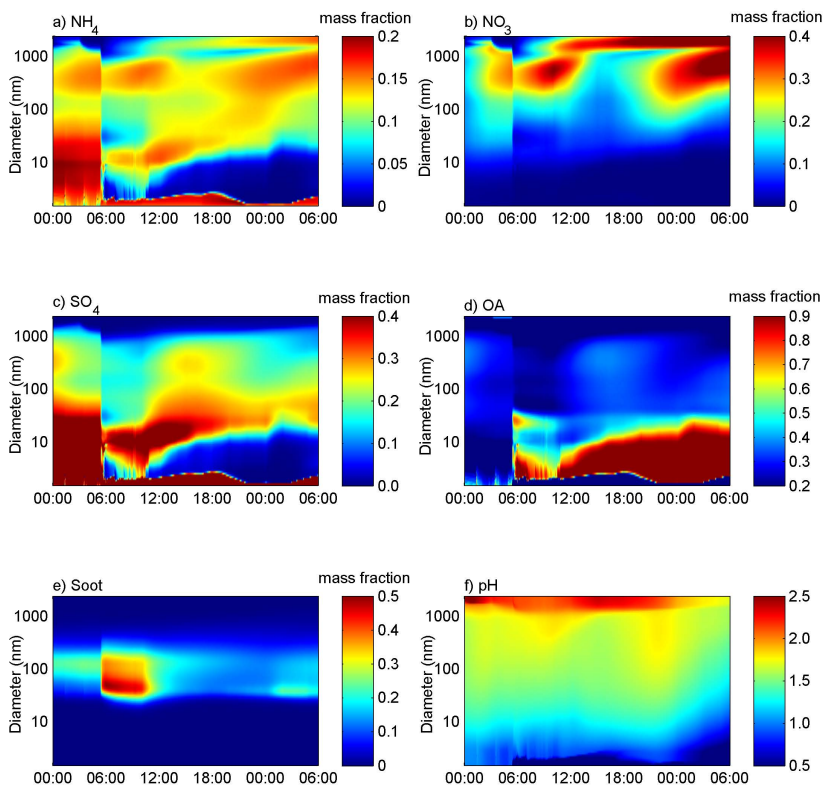

Fig. 9. Modeled size resolved particle mass fractions and $\mathrm{pH}$ in each size bin, starting $6 \mathrm{~h}$ upwind of Malmö (00:00) and ending $24 \mathrm{~h}$ downwind of Malmö, (a) for ammonium, (b) nitrate, (c) sulfate, (d) organic aerosol, (e) soot and (f) $\mathrm{pH}$.

SOA. Therefore the IVOC emissions from Malmö mainly increased the organic mass within $6 \mathrm{~h}$ downwind of the city (during the morning) while the BTX oxidation products (dominated by xylene oxidation products) mainly formed ASOA between 6 and $12 \mathrm{~h}$ downwind of the city (during the afternoon). During the evening and night (15-22 $\mathrm{h}$ downwind of the city) the $\mathrm{OH}$ concentration was very low (Fig. 7d) and therefore little ASOA was formed during this time period. $24 \mathrm{~h}$ downwind of Malmö the IVOC and BTX emissions from Malmö contributed to approximately $0.1 \mu \mathrm{g} \mathrm{m}^{-3}$ of the modeled organic PM2.5 mass, $24 \mathrm{~h}$ downwind of the city. This can be compared with the biogenic SOA formation from the BVOC emissions from the Swedish forest of $0.35 \mu \mathrm{g} \mathrm{m}^{-3}, 24 \mathrm{~h}$ downwind of Malmö.

Although the uncertainties are large, especially for the IVOC emissions, and the daily variability in the BVOC emissions can be considerable, these results indicate that during the summer months the ASOA formation more than a few hours downwind of Malmö is small compared to the BSOA which is formed from the Swedish forest emissions.

The uncertainties concerning the modeled organic aerosol mass is not just related to the SOA formation but also the magnitude of the POA emissions and the volatility of these emissions. If treating the POA emissions in and downwind of Malmö as non-volatile instead of semi-volatile, the POA mass becomes larger at and near the emission source (see Fig. 11). If the POA is considered to be semi-volatile, part of it will evaporate from the particle phase, within a time scale of approximately one hour after the emissions. The com-
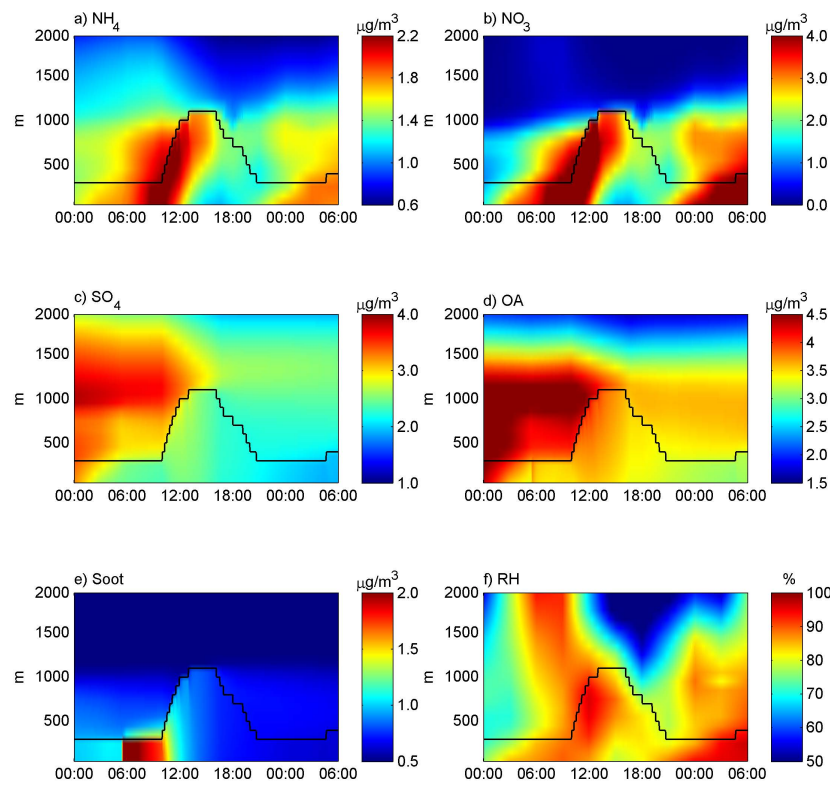

Fig. 10. Modeled PM2.5 masses of ammonium (a), nitrate (b), sulfate (c), organic aerosol (d), soot (e) and the relative humidity (f), from $6 \mathrm{~h}$ upwind of Malmö (00:00) until $24 \mathrm{~h}$ downwind of Malmö, in the vertical direction (0-2000 m a.g.1.), in the center of the urban plume. The mixing height along the trajectory is also displayed.

pounds are then oxidized in the atmosphere and form less volatile oxidized organic compounds which can condensate on the available particle surfaces. For the 2D-VBS model simulations, most of these compounds returned to the particle phase between 4 to $7 \mathrm{~h}$ downwind of Malmö, and more than $7 \mathrm{~h}$ downwind of the city, the organic PM2.5 mass from the base case simulation even exceeded the simulation with NVPOA (see Fig. 11). There are at least two reasons why the organic mass becomes larger with SVPOA instead of NVPOA. One reason is that the dry and wet deposition losses of organic gas phase compounds are insignificant compared to the dry and wet deposition losses of particles. Hence, the evaporated POA found in the gas phase will not be deposited before it re-condensates. A second reason is that the molar mass of the organic compounds increases when they are oxidized in the atmosphere.

Apart from the uncertainties related to the magnitude of the POA and SOA precursor emissions and their volatility, the model results also depend on the structure of the organic partitioning model (see Sect. 2.4). In Fig. 11 the difference in organic PM2.5 mass between the two-product model and 2D-VBS model base case simulation is displayed. The overall difference is relatively small and within the range of variability related to the POA volatility, and BVOC and anthropogenic VOC emissions. However, the dynamics of the organic mass formation downwind of Malmö is substantially different. Within $4 \mathrm{~h}$ downwind of the city the difference in the organic PM2.5 mass between the base case and the 


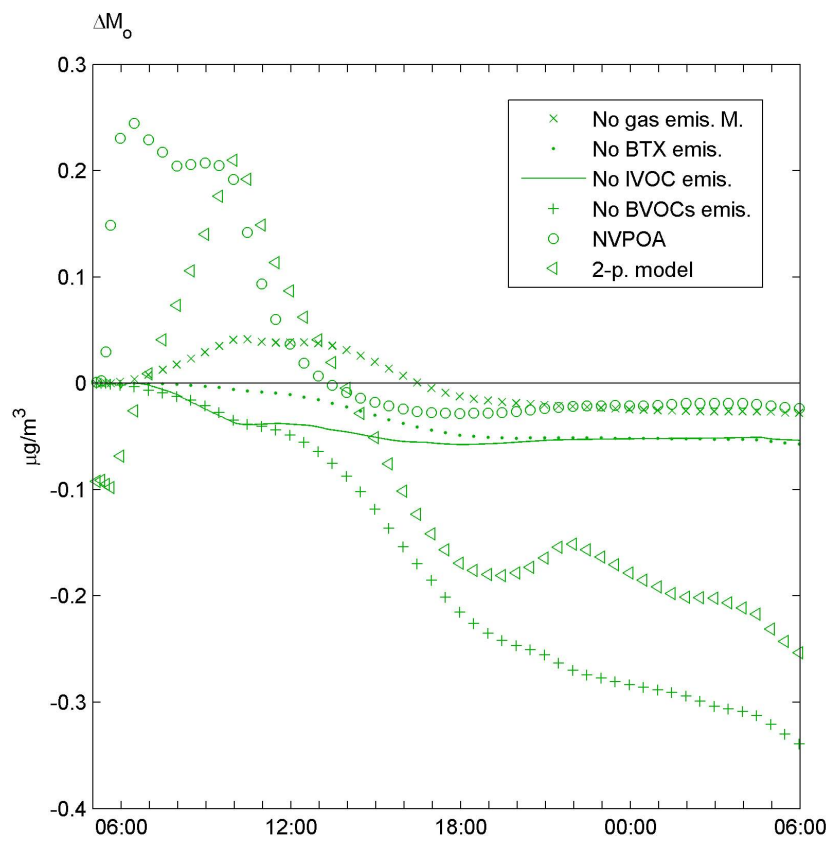

Fig. 11. Modeled organic PM2.5 mass difference $\left(\Delta \mathrm{M}_{o}\right)$ between the base case and the following case studies: (1) without any anthropogenic gas phase emissions in Malmö, (2) no BTX emissions in and downwind of Malmö, (3) no IVOC emissions in and downwind of Malmö, (4) no BVOC emissions downwind of Malmö, (5) with NVPOA in and downwind of Malmö and (6) the two-product model simulation.

two-product model simulations changes from $-0.1 \mu \mathrm{g} \mathrm{m}^{-3}$ to $0.2 \mu \mathrm{g} \mathrm{m}^{-3}$. The main reason for this is the faster recondensation of the evaporated POA and condensation of the IVOCs oxidation products with the two-product model compared to the 2D-VBS model (base case).

Both with the 2D-VBS model and the two-product model ADCHEM considers the diffusion limited condensation and evaporation of organic compounds with a wide range of volatilities. Because of the Kelvin effect more volatile compounds are shifted toward larger particle sizes than less volatile compounds. The least volatile compounds $\left(\mathrm{C}^{*}<\right.$ $10^{-1} \mu \mathrm{g} \mathrm{m}^{-3}$ ) which condense onto the Fuchs-Sutugincorrected aerosol surface area size distribution evaporate slowly, while more volatile compounds $\left(\mathrm{C}^{*}>10^{1} \mu \mathrm{g} \mathrm{m}^{-3}\right)$ quickly condensate and evaporate from the particle surfaces until equilibrium between the gas phase and all particle sizes is reached.

In Fig. 12a the size resolved organic mass fractions of oxidized compounds (O:C-ratio between 0.1 and 1 ) with different volatility $\left(\mathrm{C}^{*}\right)$ are displayed. The model results are from the base case model run with the 2D-VBS model, $24 \mathrm{~h}$ downwind of Malmö. The oxidized organic compounds originate from gas phase compounds or from POA which has evaporated. As a consequence of the Kelvin effect, the oxidized organic compounds are distributed differently depending on
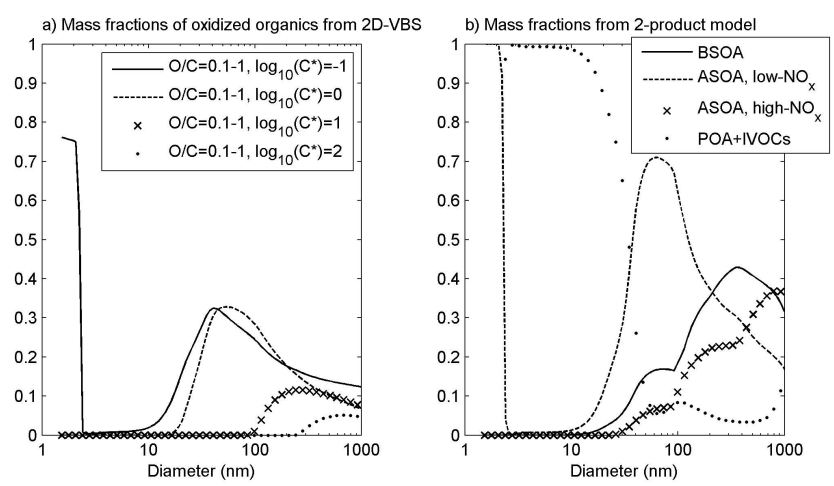

Fig. 12. (a) Size resolved organic mass fractions of oxidized compounds (O:C-ratio between 0.1 and 1 ) with different saturation concentrations $\left(\mathrm{C}^{*}\right)$. The results are from the base case simulation with the 2D-VBS model, $24 \mathrm{~h}$ downwind of Malmö. (b) Size resolved mass fractions of BSOA, ASOA from BTX oxidation through the low- and high- $\mathrm{NO}_{\mathrm{x}}$ pathway, and POA and IVOC oxidation products. The results in (b) are from the two-product model simulation, $24 \mathrm{~h}$ downwind of Malmö.

their volatility. For instance the compounds with $\mathrm{C}^{*}$ equal to 10 are not found on particles smaller than $100 \mathrm{~nm}$ in diameter while compounds with $\mathrm{C}^{*}$ equal to 0.1 are even found on the nucleation mode particles below $2 \mathrm{~nm}$ in diameter.

Figure $12 \mathrm{~b}$ gives the size resolved organic mass fractions of BSOA, ASOA from BTX oxidation products formed through the high- or low- $\mathrm{NO}_{\mathrm{x}}$ pathway, and POA and IVOCs oxidation products, modeled with the two-product model. In the two-product model the BTX oxidation products formed through the low- $\mathrm{NO}_{\mathrm{x}}$ pathway are assumed to be non-volatile $\left(C^{*}=0\right)$. Hence, these organic compounds are not affected by the Kelvin effect and can condensate even on the smallest particle sizes. The POA dominated over the SOA in the size range between 3 and $30 \mathrm{~nm}$ but contributed to less than $10 \%$ of the organic mass content between 50 and $1000 \mathrm{~nm}$ in diameter. The BSOA and ASOA compounds formed from the BTX oxidation through the high- $\mathrm{NO}_{\mathrm{x}}$ pathway have variable volatility but none of these compounds is completely non-volatile. The BSOA is mainly found on particles larger than $100 \mathrm{~nm}$ in diameter but a smaller fraction of less volatile compounds is also found on the particles between 10 and $100 \mathrm{~nm}$ in diameter. The ASOA formed from the BTX oxidation through the high- $\mathrm{NO}_{\mathrm{x}}$ pathway is separated into three distinct volatility classes. The least volatile of these compounds are found on particle sizes down to $30 \mathrm{~nm}$ in diameter, an intermediate volatile class of compounds is found on particles larger than $100 \mathrm{~nm}$ in diameter and the most volatile compounds are mainly distributed onto particles larger than $300 \mathrm{~nm}$ in diameter. 


\section{Summary and conclusions}

In this work a trajectory model for Aerosol Dynamics, gas phase CHEMistry and radiative transfer calculations (ADCHEM) was developed and evaluated. The model considers both vertical and horizontal dispersion perpendicular to an air mass trajectory. The Lagrangian approach makes the model computationally faster than available regional 3DCTMs. This enables a more detailed representation of the aerosol dynamics, gas and particle phase chemistry with size resolved partitioning of 110 different organic compounds and a fine spatial and temporal resolution. These features make it well suited for modeling of ageing processes relevant for climate and population health, from local to regional scales. Possible ADCHEM applications are:

- Studies of particle size dependent condensation and evaporation of semi-volatile gas phase species (e.g. $\mathrm{HNO}_{3}, \mathrm{NH}_{3}, \mathrm{HCl}$ and oxidation products of VOCs).

- Modeling the urban influence on the oxidizing capacity of the atmosphere (e.g. ozone, $\mathrm{OH}, \mathrm{HO}_{2}, \mathrm{NO}_{3}$, NO concentrations affecting the ASOA and BSOA formation).

- Transformation of real-world size-resolved primary particle emissions to a grid scale treated by regional and global 3D-CTMs, accounting for sub-grid scale processes.

- Studies of new particle formation and growth within urban plumes or large scale regional nucleation events.

- Estimating the urban influence on cloud condensation nuclei $(\mathrm{CCN})$ properties (indirect effect).

- Studies of the urban emissions influence on the aerosol optical properties and radiative balance (direct effect).

- Population exposure and respiratory dose studies.

When using more than 50 size bins between 1.5 and $2500 \mathrm{~nm}$ the full-stationary method gave relatively little numerical diffusion, while when using only 10 size bins the moving-center method which almost eliminates numerical diffusion was a better choice. When using 25 size bins neither of these two methods was ideal, but a combination of the two methods gave good representation of the particle number size distribution.

The dry deposition together with the vertical dilution when the mixing height increases were the processes with largest influence on the particle number size distribution and number concentration downwind of Malmö. Hence, together these processes effectively decrease the horizontal and vertical particle number concentration gradient between urban plume and the background. During the night when a residual layer is formed the dry deposition causes a significantly lower particle number concentration within the boundary layer compared to the residual layer.
When using uncoupled condensation, significantly more particle phase nitrate was formed than if assuming coupled condensation. The particle nitrate is also shifted towards larger particle sizes with uncoupled condensation compared to coupled condensation. These differences occur since the aerosol particles were not fully neutralized and the $\mathrm{pH}$ increases with the particle size. This illustrates that coupled condensation should not be used if the aerosol particles are not fully neutralized.

For the considered case study the air mass trajectory spent much time over the ocean upwind of Malmö (see Fig. 3). Here there are no or very small emissions of ammonia but relatively large emissions of $\mathrm{SO}_{2}$ from ship traffic. This can explain why the aerosol particles were not fully neutralized. If the air mass instead would have been traveling over large agricultural areas in Europe the aerosol would likely have been more neutralized and the agreement between the uncoupled and coupled condensation simulations would have been better.

The 2D-VBS model and the two-product model in ADCHEM consider the diffusion limited condensation and evaporation of 110 and 40 organic compounds respectively, with a wide range of volatilities. This gives a realistic particle size dependent and dynamic organic mass partitioning which cannot be treated by available equilibrium models. The dynamic and size resolved organic mass partitioning is especially important during the ageing of SVPOA, which starts with diffusion limited evaporation, followed by oxidation reactions in the gas phase and then finally the re-condensation of the formed oxidized organic compounds. Unfortunately, it is computationally expensive to keep track of all organic compounds in each size bin and each grid cell, and hence this dynamic and size resolved partitioning of organic compounds can probably not be used in available regional 3D-CTMs.

Lane et al. (2008) compared the modeled organic aerosol from the PMCAMx 3D-CTM using the two-product model or VBS approach and concluded that the model framework (e.g. two-product model or VBS) is less important than the parameters used in the model (e.g. saturation concentrations and yields). The good agreement of the total organic particle mass found between 2D-VBS and the two-product model simulations in this study support this finding. However, since the two-product model used in ADCHEM assumes that it is the first oxidation reaction that is rate limiting and determines the properties of the final products, the dynamics of the organic mass formation downwind of Malmö cannot be as precisely represented as with the $2 \mathrm{D}$-VBS model. The largest advantage with the two-product model compared to the 2D-VBS model is that the simplified oxidation mechanism makes it computationally feasible to keep track of the origin to the formed OA (e.g. if it is BSOA, ASOA or POA). Hence, the two-product model and the 2D-VBS models used in ADCHEM are good complement to each other, and the choice of model should be made according to the type of application. 
For more information about the Malmö emissions influence on climate relevant particle properties within the urban plume, the reader is referred to Roldin et al. (2011), where ADCHEM is applied to 26 trajectories for the period April 2005 to October 2006.

\section{Appendix A}

\section{Atmospheric diffusion}

The kinematic heat flux $\left(F_{\mathrm{H}}\right)$ is used in the model when calculating the eddy diffusivity coefficients and the dry deposition velocities. The kinematic heat flux in the surface layer can be approximated with Eq. (A1) (Stull Appendix H, 2000).

$$
F_{\mathrm{H}}=-K_{\mathrm{H}} \cdot \frac{\Delta \theta}{\Delta z}, \quad K_{\mathrm{H}}=\kappa^{2} \cdot z^{2} \cdot\left|\frac{\Delta v}{\Delta z}\right|
$$

$v$ is the horizontal wind speed, $\kappa$ is the von Kármán constant, $K_{\mathrm{H}}$ is the heat eddy viscosity, $z$ is the altitude and $\theta$ is the potential temperature.

The eddy diffusivity in the vertical direction in the boundary layer is calculated using Eqs. (A2), (A3) and (A4) for stable, near neutral and unstable conditions, respectively. Equation (A2) is adopted from Businger and Arya, 1974, Eq. (A3) from Myrup and Ranzieri, 1976 and Eq. (A4) from Tirabassi and Rizza, 1997. Above the boundary layer the eddy diffusivity is approximated using Eq. (A2).

$$
\begin{aligned}
& K_{z}=\frac{\kappa u_{*} z}{0.74+4.7(z / L)} \exp \left(\frac{-8 f z}{u_{*}}\right) \quad \frac{h}{L}>10
\end{aligned}
$$

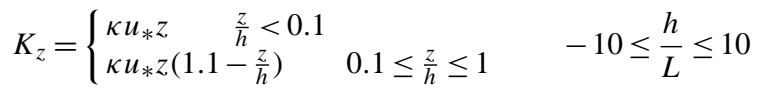

$$
\begin{aligned}
& K_{z}=\kappa w_{*} z\left(1-\frac{z}{h}\right) \quad \frac{h}{L}<-10
\end{aligned}
$$

$h$ is the mixing height, $u_{*}$ is the friction velocity, $f$ is the Coriolis parameter, $L$ is the Monin-Obukhov length and $w_{*}$ is the convective scaling velocity.

The horizontal eddy diffusivity is estimated using Eq. (A5), if the flux Richardson number is negative (unstable atmosphere) (Seinfeld and Pandis, 2006). If the atmosphere is stable the horizontal diffusivity is set as two times the largest vertical eddy diffusivity (Tirabassi and Rizza, 1997).

$$
K_{y}=0.1 w_{*} h
$$

\section{Appendix B}

\section{Numerical solution to the atmospheric diffusion equation}

The atmospheric diffusion equation (Eq. 1) is discretized using the second order five-point formula (Eq. B1).

$$
\begin{aligned}
& \text { For } \quad \mathrm{k}=1, \ldots . \mathrm{N}, \quad \mathrm{n}=1, \ldots . \mathrm{N} \\
& \frac{\Delta c}{\Delta t}{ }_{k, n}=\frac{1}{\Delta z^{2}}\left(K_{z, k-\frac{1}{2}} c_{k-1, n}+K_{z, k+\frac{1}{2}, n} c_{k+1, n}\right) \\
& +\frac{1}{\Delta y^{2}}\left(K_{y, n-\frac{1}{2}} c_{k, n-1}+K_{y, n+\frac{1}{2}} c_{k, n+1}\right) \\
& -\frac{1}{\Delta z^{2}}\left(K_{z, k-\frac{1}{2}}+K_{z, k+\frac{1}{2}}\right) c_{k, n}-\frac{1}{\Delta y^{2}}\left(K_{y, n-\frac{1}{2}}+K_{y, n+\frac{1}{2}}\right)+h_{k, n}
\end{aligned}
$$

$N$ is the number of grid cells in the vertical and horizontal direction. $h_{k, n}$ is the rest terms containing the boundary values. If dry deposition and emissions are included directly in the atmospheric diffusion equation these terms will enter here.

As horizontal boundary conditions the concentration gradient $\partial c / \partial y$ was set to zero. If the ground-level emission rate $(E)$ and dry deposition are included in the boundary conditions at the ground they are described by Eq. (B2). The boundary conditions at the top of the vertical model domain are given by Eq. (B3).

$$
\begin{aligned}
& v_{d} c-K_{z} \frac{\partial c}{\partial z}=E \\
& \frac{\partial c}{\partial z}=10^{-3} \mathrm{~cm}^{-3} \mathrm{~m}^{-1}
\end{aligned}
$$

$v_{d}$ and $E$ is the dry deposition velocity and emission of particles or gases.

Equation (B1) can be written in matrix form with one matrix for each space dimension $\left(\mathbf{T}_{z}\right.$ and $\left.\mathbf{T}_{y}\right)$ (Eq. B4).

$\frac{\Delta c}{\Delta t}=\left(\frac{1}{\Delta z^{2}} \mathbf{T}_{z}+\frac{1}{\Delta y^{2}} \mathbf{T}_{y}\right) c+h_{z, y}$

For each time step that the model takes, Eq. (B4) is solved using the second order implicit trapezoidal rule (CrankNicolson method). The procedure is described by Iserles (2004). Equation (B5) is the final expression used to solve the atmospheric diffusion equation in 2 -space dimensions.

$$
\begin{aligned}
& c^{j+1}=\left[1-\frac{1}{2} \frac{\Delta t}{\Delta z^{2}} \mathbf{T}_{z}\right]^{-1}\left[1+\frac{1}{2} \frac{\Delta t}{\Delta z^{2}} \mathbf{T}_{z}\right]\left[1-\frac{1}{2} \frac{\Delta t}{\Delta y^{2}} \mathbf{T}_{y}\right]^{-1} \\
& \cdot\left[1+\frac{1}{2} \frac{\Delta t}{\Delta y^{2}} \mathbf{T}_{y}\right] \cdot\left(c^{j}+\frac{1}{2} \Delta t \cdot h_{z, y}^{j}\right)+\frac{1}{2} \Delta t \cdot h_{z, y}^{j+1}
\end{aligned}
$$

\section{Appendix C}

\section{Brownian coagulation}

The coagulation coefficient between two particles of same or different diameters is given by Eq. (C1). $\beta$ is the Fuchs correction factor, given by Eq. (C2) (Seinfeld and Pandis, 2006).

$$
K_{i j}=2 \pi \beta_{i j}\left(D_{\mathrm{p} i} D_{i}+D_{\mathrm{p} i} D_{j}+D_{\mathrm{p} j} D_{i}+D_{\mathrm{p} j} D_{j}\right)
$$




$$
\begin{aligned}
& \beta_{i j}=\left[\frac{D_{\mathrm{p} i}+D_{\mathrm{p} j}}{D_{p 1}+D_{\mathrm{p} i}+2\left(\delta_{i}^{2}+\delta_{j}^{2}\right)^{1 / 2}}+\frac{8 \alpha\left(D_{i}+D_{j}\right)}{\left(\bar{c}_{i}^{2}+\bar{c}_{j}^{2}\right)^{1 / 2}\left(D_{\mathrm{p} i}+D_{\mathrm{p} j}\right)}\right]^{-1} \\
& \bar{c}_{i}=\left(\frac{8 k T}{\pi m_{i}}\right)^{1 / 2}, \\
& \delta_{i}=\frac{1}{3 D_{\mathrm{p} i} l_{i}}\left[\left(D_{\mathrm{p} i}+l_{i}\right)^{3}-\left(D_{\mathrm{p} i}^{2}+l_{i}^{2}\right)^{3 / 2}\right]-D_{\mathrm{p} i}, l_{i}=\frac{8 D_{i}}{\pi \bar{c}_{i}}
\end{aligned}
$$

$\alpha$ is the collision efficiency which can be assumed to be 1 for all particle sizes (Clement et al., 1996), $m_{i}$ is the singe particle mass in size bin $i, \bar{c}_{i}$ is the mean particle velocity and $l_{i}$ is the mean free path.

Equation $(\mathrm{C} 1)$ is used to calculate a matrix containing all possible coagulation rates between two particles with different or equal diameters for the finite diameter size bins considered.

The splitting parameters used to divide the formed single particle volumes into the fixed size bins, are calculated with Eq. (C3).

$$
\begin{gathered}
y_{1, i, j}=\frac{\left(V_{\mathrm{p}, i+1}-V_{\mathrm{p}, \text { coag }, i, j}\right)}{\left(V_{\mathrm{p} i+1}-V_{\mathrm{p} i}\right)}, \quad V_{\mathrm{p}, \mathrm{coag}, i, j}=V_{\mathrm{p}, i}+V_{\mathrm{p}, j} \\
y_{2, i, j}=1-y_{1, i, j}
\end{gathered}
$$

$y_{1, i}$ is the fraction of the single particle volume of the formed particle $\left(V_{\mathrm{p}, \text { coag }, i, j}\right)$ which will fall into the smaller size bin $i$ and $y_{2, i}$ is the fraction of particle volume which will fall into the larger size bin $i+1$.

The coagulation sink and source are described by Eqs. (C4) and (C5). Combining the coagulation sources and sinks gives the final equations used to calculate new particle size distributions, in each grid cell (Eq. C6).

$$
\begin{aligned}
& \text { Coag }_{\text {sink }, i, j}=K_{i j} c_{i} \cdot c_{j} \\
& \text { Coag }_{\text {source }, i, j}=a_{i, j} K_{i j} c_{i} \cdot c_{j}, \text { if } \\
& i=j, \quad a_{i, j}=0.5, \text { else } a_{i, j}=1 \\
& c_{i}=c_{i}+\sum_{j}^{N}\left(y_{1, i, j} \cdot \operatorname{Coag}_{\text {source }, i, j}+y_{2, i-1, j} .\right. \\
& \text { Coag } \left._{\text {source }, i-1, j}-\operatorname{Coag}_{\sin k, i, j}\right) \cdot \Delta t
\end{aligned}
$$

The volume change of different species $(k)$ in the aerosol particle phase due to coagulation between particles in size bin $i$ and $j$ is derived with Eq. (C7).

$$
\begin{aligned}
& \frac{d V_{i, j, k}}{d t}=y_{1 i, j} \cdot \text { Coag }_{\text {source }, i, j} \cdot x_{\text {coag } i, k} \cdot V_{\mathrm{p}, \text { coag }, i} \\
& +y_{2 i-1, j} \cdot \operatorname{Coag}_{\text {source }, i-1, j} \cdot x_{\text {coag } i-1, k} \cdot V_{\mathrm{p}, \text { coag }, i-1} \\
& - \text { Coag }_{\text {sink }, i, j} \cdot V_{\mathrm{p}, i} \cdot x_{i, k}
\end{aligned}
$$

$x_{i, k}$ is the volume fraction of species $k$ in size bin $i$ and $x_{\text {coag, }, i, k}$ is the volume fraction of species $k$ in the formed particle.

Equation (C8) gives the volume of species $k$ in each size bin.

$$
V_{i, k}=V_{\mathrm{p}, i} \cdot x_{i, k}+\sum_{j}^{N} \frac{d V_{i, j, k}}{d t} \cdot \Delta t
$$

\section{Appendix D}

\section{Dry deposition velocities of particles}

Equation (D1) gives the dry deposition loss rate $\left(v_{d}\right)$ of particles. $r_{a}$ is the surface layer resistance, $r_{b}$ the quasi-laminar layer resistance and $v_{s}$ is the settling velocity.

$v_{d}=\frac{1}{r_{a}+r_{b}+r_{a} r_{b} v_{s}}+v_{s}$

The settling velocity is given by Eq. (D2).

$v_{s}=\frac{\rho_{p} D_{\mathrm{p}}^{2} g C_{c}}{18 \mu}$

$\rho_{p}$ is the particle density, $\mu$ is the dynamic viscosity, $C_{c}$ is the Cunningham slip correction factor and $g$ is the acceleration of gravity

The surface layer resistance can be expressed by Eqs. (D3) and (D4) for stable and unstable atmosphere, respectively (Seinfeld and Pandis, 2006).

$r_{a}=\frac{1}{\kappa u_{*}}\left(\ln \left(\frac{z}{z_{0}}\right)+4.7\left(R f_{s}-R f_{0}\right)\right.$

$r_{a}=\frac{1}{\kappa u_{*}}\left(\ln \left(\frac{z}{z_{0}}\right)+\ln \left(\frac{\left(\eta_{0}^{2}+1\right)\left(\eta_{0}+1\right)^{2}}{\left(\eta_{s}^{2}+1\right)\left(\eta_{s}+1\right)^{2}}\right)+2\left(\tan ^{-1} \eta_{s}-\tan ^{-1} \eta_{0}\right)\right)$

$\eta_{0}=\left(1-15 R f_{0}\right)^{1 / 4}, \eta_{s}=\left(1-15 R f_{s}\right)^{1 / 4}, R f_{0}=\frac{z_{0}}{L}, R f_{s}=\frac{z_{s}}{L}$

$\kappa=0.4$ (von Karman constant)

$z_{0}$ is the roughness length and $u_{*}$ is the friction velocity. The surface layer height $\left(z_{s}\right)$ can be approximated as one tenth of the total mixing height (Seibert et al., 1997). $R f_{0}$ is the non-dimensional flux Richardson number at the roughness length scale height $\left(\mathrm{z}_{0}\right)$ and $R f_{s}$ is the flux Richardson number at the surface layer height. If $R f$ is larger than zero, the atmosphere is stable and Eq. (D3) is used, and if $R f$ is smaller than zero, the atmosphere is unstable and Eq. (D4) is used instead.

The quasi-laminar resistance is calculated with Eq. (D5) over land (Zhang et al., 2001, Seinfeld and Pandis, 2006) and with Eq. (D6) over ocean (Slinn and Slinn, 1980).

$$
\begin{aligned}
r_{b} & =\frac{1}{3 u_{*} R_{1}\left(S c^{-\gamma}+(S t /(\alpha+S t))^{2}+0.5\left(D_{\mathrm{p}} / A\right)^{2}\right)} \\
R_{1} & =\exp \left(-S t^{1 / 2}\right) \\
r_{b} & =\frac{\kappa \cdot v}{u_{*}^{2}} \frac{1}{\left(S c^{-1 / 2}+10^{-3 / S t}\right)}
\end{aligned}
$$

$R_{1}$ is the fraction of particles that stick to the surface upon contact. $A, \alpha$ and $\gamma$ are surface specific parameters given by Zhang et al. (2001) for 12 different land use categories. St is the Stokes number and $S c$ is the Schmidt number. 
Table E. Explicit scheme used to estimate the particle salt molar composition.

\begin{tabular}{|c|c|c|c|c|}
\hline Salt & $\begin{array}{l}\text { if } n_{\mathrm{S}(\mathrm{VI})}> \\
n_{\mathrm{NH}_{4}}+n_{\mathrm{Na}}\end{array}$ & $\begin{array}{l}\text { if } n_{\mathrm{S}(\mathrm{VI})}< \\
n_{\mathrm{NH}_{4}}+n_{\mathrm{Na}} \\
\& \\
n_{\mathrm{S}(\mathrm{VI})}+n_{\mathrm{NO}_{3}} \\
>n_{\mathrm{NH}_{4}}+n_{\mathrm{Na}}\end{array}$ & $\begin{array}{l}\text { if } n_{\mathrm{S}(\mathrm{VI})}+n_{\mathrm{NO}_{3}} \\
\leq n_{\mathrm{NH}_{4}}+n_{\mathrm{Na}} \\
\& \\
2 n_{\mathrm{S}(\mathrm{VI})}+n_{\mathrm{NO}_{3}} \\
>n_{\mathrm{NH}_{4}}+n_{\mathrm{Na}}\end{array}$ & $\begin{array}{l}\text { if } 2 n_{\mathrm{S}(\mathrm{VI})}+n_{\mathrm{NO}_{3}} \\
\leq n_{\mathrm{NH}_{4}}+n_{\mathrm{Na}}\end{array}$ \\
\hline$(\mathrm{Na})_{2} \mathrm{SO}_{4}$ & 0 & 0 & $n_{\mathrm{Na}}-n_{\mathrm{Cl}}$ & $n_{\mathrm{Na}}-n_{\mathrm{Cl}}$ \\
\hline $\mathrm{NaHSO}_{4}$ & $n_{\mathrm{Na}}-n_{\mathrm{Cl}}$ & $n_{\mathrm{Na}}-n_{\mathrm{Cl}}$ & 0 & 0 \\
\hline $\mathrm{NaCl}$ & $n_{\mathrm{Cl}}$ & $n_{\mathrm{Cl}}$ & $n_{\mathrm{Cl}}$ & $n_{\mathrm{Cl}}$ \\
\hline$\left(\mathrm{NH}_{4}\right)_{2} \mathrm{SO}_{4}$ & 0 & 0 & $\begin{array}{l}n_{\mathrm{NH}_{4}}+n_{\mathrm{Na}}-n_{\mathrm{NO}_{3}} \\
-n_{\mathrm{S}(\mathrm{VI})}-n_{(\mathrm{Na})_{2} \mathrm{SO}_{4}}\end{array}$ & $n_{\mathrm{S}(\mathrm{VI})}-n_{(\mathrm{Na})_{2} \mathrm{SO}_{4}}$ \\
\hline $\mathrm{NH}_{4} \mathrm{HSO}_{4}$ & $n_{\mathrm{NH}_{4}}$ & $n_{\mathrm{S}(\mathrm{VI})}-n_{\mathrm{NaHSO}_{4}}$ & $n_{\mathrm{S}(\mathrm{VI})}-n_{\left(\mathrm{NH}_{4}\right)_{2} \mathrm{SO}_{4}}$ & 0 \\
\hline $\mathrm{H}_{2} \mathrm{SO}_{4}$ & $\begin{array}{l}n_{\mathrm{S}(\mathrm{VI})}-n_{\mathrm{NH}_{4}} \\
-n_{\mathrm{NaHSO}_{4}}\end{array}$ & 0 & 0 & 0 \\
\hline $\mathrm{NH}_{4} \mathrm{NO}_{3}$ & 0 & $n_{\mathrm{NH}_{4}}-n_{\mathrm{NH}_{4} \mathrm{HSO}_{4}}$ & $n_{\mathrm{NO}_{3}}$ & $n_{\mathrm{NO}_{3}}$ \\
\hline $\mathrm{HNO}_{3}$ & $n_{\mathrm{NO}_{3}}$ & $n_{\mathrm{NO}_{3}}-n_{\mathrm{NH}_{4} \mathrm{NO}_{3}}$ & 0 & 0 \\
\hline $\mathrm{NH}_{3}$ & 0 & 0 & 0 & $\begin{array}{l}n_{\mathrm{NH}_{4}}-n_{\mathrm{NO}_{3}} \\
-2 n_{\left(\mathrm{NH}_{4}\right)_{2} \mathrm{SO}_{4}}\end{array}$ \\
\hline
\end{tabular}

\section{Appendix E}

\section{Inorganic particle salt composition}

Table E displays the explicit scheme which is used to estimate the particle salt molar composition.

\section{Appendix F}

\section{Dry deposition velocity for gases}

The dry deposition velocities for the different gases are given by Eq. (F1) (Seinfeld and Pandis, 2006).

$v_{d}=\frac{1}{r_{a}+r_{b}+r_{c}}$

The dry deposition can be a significant loss term for acid species like $\mathrm{HNO}_{3}$ and $\mathrm{H}_{2} \mathrm{SO}_{4}$ which has a very large effective Henry's law constant. The effective Henry's law constants used for the different species in the chemical gas phase model are taken from Table 19.4 in Seinfeld and Pandis (2006) which is valid for a pH of about 6.5. For most of the species no effective Henry's law constant were found, then the Henry's law constants given by Table 5.4 in Sander et al. (2006) were used instead. For many of the hydrocarbon species no Henry's law constants were found at all. It was then assumed that their solubility in water is practically zero.

The aerodynamic resistance is a function of the stability of the atmosphere but is independent of whether it is gases or particles that are deposited. The aerodynamic resistances for gases as well as for particles are therefore given by Eqs. (D3) and (D4).

The quasi-laminar resistance for gases over land is described by Eq. (F2) (Seinfeld and Pandis, 2006). Equation (F3) gives the quasi-laminar resistance over ocean (Hicks and Liss, 1976).

$r_{b}=\frac{5 S c_{i}^{2 / 3}}{u^{*}}$

$r_{b}=\frac{1}{\kappa u^{*}} \ln \left(\frac{z_{0} \kappa u^{*}}{D}\right)$

The canopy resistance depends on the structure of the ground. For vegetated land surfaces the resistance is divided into foliar resistance and ground resistance. Canopy resistance is the sum of the foliar resistance and the ground resistance in parallel (Seinfeld and Pandis, 2006).

The foliar resistance is divided into resistance to uptake at the surface of the leaves and at the plant stomata. The stomata resistance $\left(r_{s t}\right)$ can be further divided into the stomata pore resistance $\left(r_{p}\right)$ and the mesophyll resistance $\left(r_{m}\right)$ which is the resistance to dissolution in the leaf interior (Seinfeld and Pandis, 2006). The stomata resistance is usually very important for the dry deposition of gases. Since stomata are only open during the day it will lead to a diurnal pattern in the dry deposition velocity, with considerably higher values during the day than during the night (Pirjola and Kulmala, 1998 and Seinfeld and Pandis, 2006). 
The complete surface resistance for species $i$ is given by Eq. (F4) (Seinfeld and Pandis, 2006 originaly from Wesely, 1989). Apart from the stomata resistance the surface resistance also depends on the outer surface resistance in the upper canopy $\left(r_{l u}\right)$, transfer resistance by buoyant convection $\left(r_{d c}\right)$, the resistance to uptake by leaves, twigs and other surfaces $\left(r_{c l}\right)$ and the resistance at the ground including transfer resistance due to canopy height $\left(r_{a c}\right)$ and resistance in the soil $\left(r_{g s}\right)$.

$r_{c}^{i}=\left(\frac{1}{r_{s t}^{i}}+\frac{1}{r_{l u}^{i}}+\frac{1}{r_{d c}^{i}+r_{c l}^{i}}+\frac{1}{r_{a c}^{i}+r_{g s}^{i}}\right)^{-1}$

\section{Appendix G}

\section{Radiative transfer model}

The radiative transfer equation for solar irradiance can be written as in Eq. (G1) (Jacobson, 2005).

$\mu \frac{d I_{\lambda, \mu, \phi}}{d \tau_{\lambda}}=I_{\lambda, \mu, \phi}-J_{\lambda, \mu, \phi}^{\text {diffuse }}-J_{\lambda, \mu, \phi}^{\text {direct }}$

The diffuse component is given by Eq. (G2) and the direct component by Eq. (G3).

$$
\begin{aligned}
& J_{\lambda, \mu, \phi}^{\text {diffuse }}=\sum_{k}\left(\frac{\sigma_{s, k, \lambda}}{\sigma_{\lambda}} \frac{1}{4 \pi} \int_{0}^{2 \pi} \int_{-1}^{1} I_{\lambda, \mu^{\prime}, \phi^{\prime}} P_{s, k, \lambda, \mu, \mu^{\prime}, \phi, \phi^{\prime}, d \mu^{\prime}, d \phi^{\prime}}\right) \\
& J_{\lambda, \mu, \phi}^{\text {direct }}=\frac{1}{4 \pi} E_{s, \lambda}^{-\tau_{\lambda} / \mu_{s}} \sum_{k}\left(\frac{\sigma_{s, k, \lambda}}{\sigma_{\lambda}} P_{s, k, \lambda, \mu,-\mu_{s}, \phi, \phi_{s}}\right)
\end{aligned}
$$

$\lambda$ is the wavelength of light, $I_{\lambda}$ is the the spectral radiance, $E_{s}$ is the solar irradiance, $\tau_{\lambda}$ is the optical depth, $\emptyset_{s}$ is the solar zenith angle, $\sigma$ is the extinction coefficient, $\sigma_{s}$ is the scattering coefficient, $\mu_{s}=\cos \left(\emptyset_{s}\right)$ and $\Phi_{s}$ gives the direction of the solar radiation, $\mu$ and $\Phi$ gives the orientation of the beam of interest, $\mu^{\prime}$ and $\Phi^{\prime}$ gives the direction of the diffuse radiation and $P_{s}$ is the scattering phase function, which gives the angular distribution of the scattered energy.

Approximating the integral in Eq. (G2) with quadrature two-stream equations gives Eq. (G4) (Jacobson, 2005).

$$
\begin{aligned}
& \frac{1}{4 \pi} \int_{0}^{2 \pi} \int_{-1}^{1} I_{\lambda, \mu^{\prime}, \phi^{\prime}} P_{s, k, \lambda, \mu, \mu^{\prime}, \phi, \phi^{\prime}, d \mu^{\prime}, d \phi^{\prime}} \\
& \approx\left\{\begin{array}{lll}
\frac{1+g_{a, k, \lambda}}{2} I \uparrow+\frac{1-g_{a, k, \lambda}}{2} I \downarrow & \text { upward } \\
\frac{1+g_{a, k, \lambda}}{2} I \downarrow+\frac{1-g_{a, k, \lambda}}{2} I \uparrow & \text { downward }
\end{array}\right.
\end{aligned}
$$

$I \uparrow$ is the upward radiance and $I \downarrow$ is the downward radiance.

Combining Eqs. (G2) and (G4) gives Eq. (G5).

$J_{\lambda, \mu, \phi}^{\text {diffuse }} \approx \begin{cases}\omega_{s, \lambda} \frac{1+g_{a, \lambda}}{2} I \uparrow+\omega_{s, \lambda} \frac{1-g_{a, \lambda}}{2} I \downarrow & \text { upward } \\ \omega_{s, \lambda} \frac{1+g_{a, \lambda}}{2} I \downarrow+\omega_{s, \lambda} \frac{1-g_{a, \lambda}}{2} I \uparrow & \text { downward }\end{cases}$ $\omega_{s, \lambda}=\frac{\sigma_{s, \lambda}}{\sigma_{\lambda}}$, is the single scattering albedo and $g_{a, \lambda}$ is the effective asymmetry parameter, calculated from the asymmetry parameters for gases $\left(g_{a, g, \lambda}\right)$, particles $\left(g_{a, p, \lambda}\right)$ and cloud drops $\left(g_{a, c, \lambda}\right)$ (Eq. G6).

$g_{a, \lambda}=\frac{\sigma_{s, a, \lambda} g_{a, p, \lambda}+\sigma_{s, c, \lambda} g_{a, c, \lambda}}{\sigma_{s, g, \lambda}+\sigma_{s, p, \lambda}+\sigma_{s, c, \lambda}}$

If using the quadrature approximation (Eq. G4), Eq. (G1) can be written as:

$\left\{\begin{array}{l}\mu_{1} \frac{d I \uparrow}{d \tau}=I \uparrow-\omega_{s} \frac{1+g_{a}}{2} I \uparrow-\omega_{s} \frac{1-g_{a}}{2} I \downarrow-\frac{\omega_{s}}{4 \pi}\left(1-3 g_{a} \mu_{1} \mu_{s}\right) E_{s} e^{-\tau / \mu_{s}} \\ -\mu_{1} \frac{d}{d \tau}=I \downarrow-\omega_{s} \frac{1+g_{a}}{2} I \downarrow-\omega_{s} \frac{1-g_{a}}{2} I \uparrow-\frac{\omega_{s}}{4 \pi}\left(1+3 g_{a} \mu_{1} \mu_{s}\right) E_{s} e^{-\tau / \mu_{s}}\end{array}\right.$

$\mu_{1}$ is equal to $1 / \sqrt{3}$ when using the quadrature approximation. The spectral radiation terms in Eq. (G7) can be replaced with the spectral irradiance using the conversion:

$E \uparrow=2 \pi \mu_{1} I \uparrow, \quad E \downarrow=2 \pi \mu_{1} I \downarrow$

This gives Eq. (G9) (Jacobson, 2005):

$\left\{\begin{array}{l}\frac{d E \uparrow}{d \tau}=\gamma_{1} E \uparrow-\gamma_{2} E \downarrow-\gamma_{3} \omega_{s} E_{s} e^{-\tau / \mu_{s}} \\ \frac{d E \downarrow}{d \tau}=-\gamma_{1} E \downarrow+\gamma_{2} E \uparrow+\left(1-\gamma_{3}\right) \omega_{s} E_{s} e^{-\tau / \mu_{s}}\end{array}\right.$

Where

$\gamma_{1}=\frac{1-\omega_{s}\left(1+g_{a}\right) / 2}{\mu_{1}}, \quad \gamma_{2}=\frac{\omega_{s}\left(1-g_{a}\right)}{2 \mu_{1}}, \quad \gamma_{3}=\frac{1-3 g_{a} \mu_{1} \mu_{s}}{2}$

Equation (G9) is discretized and solved according to the numerically stable scheme developed by Toon et al. (1989).

Combining the direct and the diffuse spectral radiance gives the net spectral radiation:

$I_{\text {net }}\left(\tau_{n}\right)=I \uparrow\left(\tau_{n}\right)-I \downarrow\left(\tau_{n}\right)-I_{d i r}\left(\tau_{n}\right)$

Multiplying the net spectral radiance with $4 \pi$ gives the spectral actinic flux in $\mathrm{W} \mathrm{m}^{-2} \mathrm{~nm}^{-1}$.

Tabel 4.2 in Seinfeld and Pandis (2006) originally from Fröhlich and London (1986) gives the solar spectral irradiance at the top of the atmosphere $\left(E_{\text {top }}\right)$, normalized to a solar constant $(S)$ of $1367 \mathrm{~W} \mathrm{~m}^{-2}$. Since this spectral irradiance is independent of the composition of the atmosphere, it can be used together with a radiative transfer model to predict the actinic flux at different altitudes in the atmosphere.

The solar zenith angle $\left(\Phi_{z}\right)$ is calculated with Eq. (G11) (Stull, 2000).

$$
\begin{aligned}
& \sin \left(\phi_{z}\right)=\sin (\psi) \sin \left(\delta_{s}\right)-\cos (\psi) \cos \left(\delta_{s}\right) \cos \left[\frac{360 t_{t T C}}{t_{d}}-\lambda_{e}\right] \\
& \delta_{s}=23.45 \cos \left[\frac{360(d-173)}{365}\right]
\end{aligned}
$$

$\delta_{s}$ is the solar declination angle, $\psi$ is the latitude and $\lambda_{e}$ is the longitude.

\section{Supplementary material related to this article is available online at: http://www.atmos-chem-phys.net/11/5867/2011/ acp-11-5867-2011-supplement.pdf.}


Acknowledgements. This work has been supported by the European Commission 6th Framework program projects: EUCAARI, contract no 036833-2 (EUCAARI) and EUSAAR, contract no 026140 (EUSAAR). We also gratefully acknowledge the support by the Swedish Research Council through project no 2007-4619, the Strategic Research Program MERGE: Modeling the Regional and Global Earth System and the Lund University center for studies of Carbon cycle and Climate Interactions, LUCCI. The Swedish Research Council also funded the purchase of the HR-ToF-AMS instrument through Research Equipment Grant no 2006-5940. The DMPS measurements at Vavihill were supported by the Swedish Environmental Protection Agency within the Swedish Environmental Monitoring Program. The support by the Swedish Research Council for Environment, Agricultural Sciences and Spatial Planning (Formas) through project no 2009-615 is also gratefully acknowledged.

The authors would also like to thank Henrik Nilsson and Susanna Gustafsson at Environmental Dept., City of Malmö for the gas and meteorological measurements in Malmö and the gas and PM emission data for southern Sweden, Emilie Stroh at the Dept. of Epidemiology and environmental medicine at Lund University for help with the implementation of the southern Sweden emission data, Matthias Ketzel and Fenjuan Wang from Danish National Environmental Research Institute for help with the Danish anthropogenic gas and particle emissions and David Simpson from the Norwegian Meteorological Institute, Oslo, and Dept. Earth and Space Science, Chalmers, Gothenburg for help with the SOA partitioning theory.

Edited by: A. Wiedensohler

\section{References}

Arneth, A., Niinemets, Ü., Pressley, S., Bäck, J., Hari, P., Karl, T., Noe, S., Prentice, I. C., Sera, D., Hickler, T., Wolf, A., and Smith, B.: Process-based estimates of terrestrial ecosystem isoprene emissions: incorporating the effects of a direct $\mathrm{CO}_{2}$-isoprene interaction, Atmos. Chem. Phys., 7, 31-53, doi:10.5194/acp-731-2007, 2007.

Arneth, A., Schurgers, G, Hickler, T, and Miller, P. A.: Effects of species composition, land surface cover, $\mathrm{CO}_{2}$ concentration and climate on isoprene emissions from European forests, Plant Biology, 10, 150-162, doi:110.1055/s-2007-965247, 2008.

Atkinson, R.: Gas-phase tropospheric chemistry of volatile organic compounds 1. Alkanes and alkenes, J. Phys. Chem. Ref. Data, 26, 215-290, 1997.

Atkinson, R. and Arey, J.: Gas-phase tropospheric chemistry of biogenic volatile organic compounds: a review, Atmos. Environ., 37, 197-219, 2003.

Atkinson, R., Baulch, D. L., Cox, R. A., Crowley, J. N., Hampson, R. F., Hynes, R. G., Jenkin, M. E., Rossi, M. J., and Troe, J.: Evaluated kinetic and photochemical data for atmospheric chemistry: Volume I-gas phase reactions of $\mathrm{O}_{\mathrm{x}}, \mathrm{HO}_{\mathrm{x}}, \mathrm{NO}_{\mathrm{x}}$ and $\mathrm{SO}_{\mathrm{x}}$ species, Atmos. Chem. Phys., 4, 1461-1738, doi:10.5194/acp-41461-2004, 2004.

Boy, M., Hellmuth, O., Korhonen, H., Nilsson, E. D., ReVelle, D., Turnipseed, A., Arnold, F., and Kulmala, M.: MALTE - model to predict new aerosol formation in the lower troposphere, At- mos. Chem. Phys., 6, 4499-4517, doi:10.5194/acp-6-4499-2006, 2006.

Bromley, L. A.: Thermodynamic properties of strong electrolytes in aqueous solutions, AIChE J., 19, 313-320, 1973.

Businger, J. A. and Arya, S. P. S.: Height of the mixed layer in the stably stratified planetary boundary layer, Adv. Geophys., 18A, 73-92, 1974.

Calvert, J. G., Atkinson, R., Becker, K. H., Kamens, R. M., Seinfeld, J. H., Wallington, T. J., and Yarwoord, G.: The Mechanisms of Atmospheric Oxidation of Aromatic Hydrocarbons, Oxford University Press, New York, 556 pp., 2002.

Clement, F. C., Kulmala, M., and Vesala, T.: Theoretical consideration on sticking probabilities, J. Aerosol Sci., 27(6), 869-882, 1996.

Cotte, H., Devaux, C., and Carlier, P.: Transformation of Irradiance Measurements into Spectral Actinic Flux for Photolysis Rates Determination, J. Atmos. Chem., 26, 1-28, 1997.

Donahue, N. M., Robinson, A. L., Stanier, C. O., and Pandis, S. N.: Coupled partitioning, dilution, and chemical aging of semivolatile organics, Environ. Sci. Technol., 40, 2635-2643, 2006.

Doran, J. C., Barnard, J. C., Arnott, W. P., Cary, R., Coulter, R., Fast, J. D., Kassianov, E. I., Kleinman, L., Laulainen, N. S., Martin, T., Paredes-Miranda, G., Pekour, M. S., Shaw, W. J., Smith, D. F., Springston, S. R., and Yu, X.-Y.: The T1-T2 study: evolution of aerosol properties downwind of Mexico City, Atmos. Chem. Phys., 7, 1585-1598, doi:10.5194/acp-7-1585-2007, 2007.

Draxler, R. R. and Rolph, G. D.: HYSPLIT (Hybrid Single-Particle Lagrangian Integrated Trajectory) Model access via NOAA ARL READY Wedsite (http://ready.arl.noaa.gov/HYSPLIT. php), NOAA Air Resources Laboratory, Silver Spring, MD, 8:26 AM, Tuesday, March 01, 2011.

Epstein, S., Riipinen, I., and Donahue, N. M.: A Semiempirical Correlation between Enthalpy of Vaporization and Saturation Concentration for Organic Aerosol, Environ. Sci. Technol., 44, 743-748, 2010.

Fitzgerald, J. W., Hoppel, W. A., and Gelbard, G.: A onedimensional sectional model to simulate multicomponent aerosol dynamics in the marine boundary layer 1 . Model description, J. Geophys. Res., 103, 16085-16102, 1998.

Fröhlich, C. and London, J. (Eds.): Revised Instruction Manual on Radiation Instruments and Measurements, World Climate Research Program (WCRP) Publication Series 7, World Meteorological Organization/TD No. 149, Geneva, 1986.

Grieshop, A. P., Miracolo, M. A., Donahue, N. M., and Robinson, A. L.: Constraning the Volatility Distribution and Gas-Particle Partitioning of Combustion Aerosols Using Isothermal Dilution and Thermodenuder Measurements, Environ. Sci. Technol., 43, 4750-4756, 2009.

Griffin, R. J., Cocker III, D. R., Flagan, R. C., and Seinfeld, J. H.: Organic aerosol formation from the oxidation of biogenic hydrocarbons, J. Geophys. Res., 107(D3), 3555-3567, 1999.

Guenther, A.: Seasonal and Spatial Variations in Natural Volatile Organic Compound Emissions, Ecol. Appl., 7, 34-45, 1997.

Gustafsson, S.: Uppbyggnad och validering av emissionsdatabas avseende luftföroreningar för Skåne med basår, Licentiat Dissertation at National Environmental Research Institute, Lund University, $\mathrm{nr}$ 9, 2001. 
Haylock, M., Hofstra, N., Klein Tank, A., Klok, E., Jones, P., and New, M. A.: European daily high-resolution gridded data set of surface temperature and precipitation for 1950-2006, J. Geophys. Res., 113, D20119, doi:10.1029/2008JD010201, 2008.

Henze, D. K. and Seinfeld, J. H.: Global secondary organic aerosol from isoprene oxidation, Geophys. Res. Lett., 33, L09812, doi:10.1029/2006GL025976, 2006.

Henze, D. K., Seinfeld, J. H., Ng, N. L., Kroll, J. H., Fu, T.-M., Jacob, D. J., and Heald, C. L.: Global modeling of secondary organic aerosol formation from aromatic hydrocarbons: highvs. low-yield pathways, Atmos. Chem. Phys., 8, 2405-2420, doi:10.5194/acp-8-2405-2008, 2008.

Hicks, B. B. and Liss, P. S.: Transfer of $\mathrm{SO}_{2}$ and other reactive gases across the air-sea interface, Tellus, 28, 348-354, 1976.

Hodzic, A., Vautard, R., Chazette, P., Menut, L., and Bessagnet, B.: Aerosol chemical and optical properties over the Paris area within ESQUIF project, Atmos. Chem. Phys., 6, 3257-3280, doi:10.5194/acp-6-3257-2006, 2006.

Hodzic, A., Jimenez, J. L., Madronich, S., Aiken, A. C., Bessagnet, B., Curci, G., Fast, J., Lamarque, J.-F., Onasch, T. B., Roux, G., Schauer, J. J., Stone, E. A., and Ulbrich, I. M.: Modeling organic aerosols during MILAGRO: importance of biogenic secondary organic aerosols, Atmos. Chem. Phys., 9, 6949-6981, doi:10.5194/acp-9-6949-2009, 2009.

Iserles, A.: A First Course in the Numerical Analysis of Differential Equations, Cambridge University Press, Cambridge, United Kingdom and New York, NY, USA, ISBN: 0521 55376 8, 2004.

Jacobson, M. Z.: Numerical techniques to solve condensational and dissolutional growth equations when growth is coupled to reversible aqueous reactions, Aerosol Sci. Technol., 27, 491-498, 1997.

Jacobson, M. Z. and Seinfeld, J. H.: Evolution of nanoparticle size and mixing state near the point of emission, Atmos. Environ., 38, 1839-1850, 2004.

Jacobson, M. Z.: A Solution to the Problem of Nonequilibrium Acid/Base Gas-Particle Transfer at Long Time Step, Aerosol Sci. Technol., 39, 92-103, 2005a.

Jacobson, M. Z.: Fundamentals of Atmospheric Modelling ( $2^{\text {nd }}$ edition), Cambridge University Press, Cambridge, United Kingdom and New York, NY, USA, ISBN: 052154865 9, 2005b.

Jimenez, J. L., Canagaratna, M. R., Donahue, N. M., Prevot, A. S. H., Zhang, Q., Kroll, J. H., DeCarlo, P. F., Allan, J. D., Coe, H., Ng, N. L., Aiken, A. C., Docherty, K. S., Ulbrich, I. M., Grieshop, A. P., Robinson, A. L., Duplissy, J., Smith, J. D., Wilson, K. R., Lanz, V. A., Hueglin, C., Sun, Y. L., Tian, J., Laaksonen, A., Raatikainen, T., Rautiainen, J., Vaattovaara, P., Ehn, M., Kulmala, M., Tomlinson, J. M., Collins, D. R., Cubison, M. J., Dunlea, E. J., Huffman, J. A., Onasch, T. B., Alfarra, M. R., Williams, P. I., Bower, K., Kondo, Y., Schneider, J., Drewnick, F., Borrmann, S., Weimer, S., Demerjian, K., Salcedo, D., Cottrell, L., Griffin, R., Takami, A., Miyoshi, T., Hatakeyama, S., Shimono, A., Sun, J. Y, Zhang, Y. M., Dzepina, K., Kimmel, J. R., Sueper, D., Jayne, J. T., Herndon, S. C., Trimborn, A. M., Williams, L. R., Wood, E. C., Middlebrook, A. M., Kolb, C. E., Baltensperger, U., and Worsnop, D. R.: Evolution of Organic Aerosols in the Atmosphere, Science, 326, 1525-1529, 2009.

Kittelson, D. B., Watts, W., and Johnson, J.: Diesel aerosol sampling methodology, CRC E-43 Final Report, University of Minnesota, 2002.
Korhonen, H.: Model studies on the size distribution dynamics of atmospheric aerosols, Report series in aerosol science, No 65, Finnish association for aerosol research, ISBN: 952-5027-46-5, 2004a.

Korhonen, H., Lehtinen, K. E. J., and Kulmala, M.: Multicomponent aerosol dynamics model UHMA: model development and validation, Atmos. Chem. Phys., 4, 757-771, doi:10.5194/acp-4757-2004, 2004b.

Kristensson, A., Johansson, C., Westerholm, R., Swietlicki, E., Gidhagen, L., Widequist, U., and Vesely, V.: Real-world traffic emission factors of gases and particles measured in a road tunnel in Stockholm, Sweden, Atmos. Environ., 38, 657-673, 2004.

Kristensson, A.: Aerosol Particle Sources Affecting the Swedish Air Quality at Urban and Rural Level, Doctoral Dissertation at Department of Physics, Lund University, ISBN: 91-628-6573-0, 2005.

Kristensson, A., Dal Maso, M., Swietlicki, E., Hussein, T., Zhou, J., Kerminen, V.-M., and Kulmala, M.: Characterization of new particle formation events at a background site in Southern Sweden: relation to air mass history, Tellus, 60B, 330-344, 2008.

Kulmala, M., Lehtinen, K. E. J., and Laaksonen, A.: Cluster activation theory as an explanation of the linear dependence between formation rate of $3 \mathrm{~nm}$ particles and sulphuric acid concentration, Atmos. Chem. Phys., 6, 787-793, doi:10.5194/acp-6-787-2006, 2006.

Laakso, L., Grönholm, T., Rannik, Ü., Kosmale, M., Fiedler, V., Vehkamäki, H., and Kulmala, M.: Ultrafine particle scavening coefficients calculated from 6 years field measurements, Atmos. Environ., 37, 3605-3613, 2003.

Lane, T. E., Donahue, N. M., and Pandis, S. N.: Simulating secondary organic aerosol formation using the volatility basis-set apporach in a chemical transport model, Atmos. Environ., 42, 7439-7451, 2008.

Moldanová, J., Fridell, E., Popovicheva, O., Demirdjian, B., Tishkova, V., Faccinetto, A., and Focsa, C.: Characterisation of particulate matter and gaseous emissions from a large ship diesel engine, Atmos. Environ., 43, 2632-2641, 2009.

Myrup, L. O. and Ranzieri, A. J.: A Consistent Scheme for Estimating Diffusivities to Be Used in Air Quality Models, Report CADOT-TL-7169-3-76-32, California Department of Transportation, Sacramento, 1976.

McMurry, P. H. and Friedlander, S. K.: New particle formation in the presence of an aerosol, Atmos. Environ., 13, 1635-1651, 1979.

Mårtensson, E. M., Nilsson, E. D, de Leeuw, G., Cohen, L. H., and Hansson, H.-C.: Laboratory simulations and parameterization of the primary marine aerosol production, J. Geophys. Res., 108(D9), 4297, doi:10.1029/2002JD002263, 2003.

Ng, N. L., Kroll, J. H., Chan, A. W. H., Chhabra, P. S., Flagan, R. C., and Seinfeld, J. H.: Secondary organic aerosol formation from m-xylene, toluene, and benzene, Atmos. Chem. Phys., 7, 3909-3922, doi:10.5194/acp-7-3909-2007, 2007.

Niinemets, Ü., Tenhunen, J. D., Harley, P. C., and Steinbrecher, R.: A model of isoprene emissions based on energetic requirements for isoprene synthesis and leaf photosynthetic properties for Liquidambar and Quercus, Plant Cell and Environ., 22, 1319-1335, 1999.

Niinemets, U., Seufert, G., Steinbrecher, R., and Tenhunen, J.: A model coupling foliar monoterpene emissions to leaf pho- 
tosynthetic characteristics in Mediterranean evergreen Quercus species, New Phytol., 153, 257-275, 2002.

Nolte, C. G., Bhave, P. V., Arnold, J. R., Dennis, R. L., Zhang, K. M., and Wexler, A. S.: Modeling urban and regional aerosolsApplication of the CMAQ-UCD Aerosol Model to Tampa, a coastal urban site, Atmos. Environ., 42, 3179-3191, 2008.

O’Dowd, C. D., Facchini, M. C., Cavalli, F., Ceburnis, D., Mircea, M., Decesari, S., Fuzzi, S., Yoon, J. Y., and Putaud, J.-P.: Biogenically driven organic contribution to marine aerosol, Nature, 431, 676-680, 2004.

Odum, J. R., Hoffmann, T., Bowman, F., Collins, D., Flagan, R. C., and Seinfeld, J. H.: Gas/Particle Partitioning and Secondary Organic Aerosol Yields, Environ. Sci. Technol., 30, 2580-2585, 1996.

Pankow, J. F.: An absorption model of the gas/aerosol partitioning involved in the formation of secondary organic aerosol, Atmos. Environ., 28, 189-193, 1994.

Pankow, J. F. and Asher, W. E.: SIMPOL.1: a simple group contribution method for predicting vapor pressures and enthalpies of vaporization of multifunctional organic compounds, Atmos. Chem. Phys., 8, 2773-2796, doi:10.5194/acp-8-27732008, 2008.

Paasonen, P., Sihto, S.-L., Nieminen, T., Vuollekoski, H., Riipinen, I., Plass-Dülmer, C., Berresheim, H., Birmili, W., and Kulmala, M.: Connection between new particle formation and sulphuric acid at Hohenpeissenberg (Germany) including the influence of organic compounds, Boreal Environmental Research, 14, 616629, 2009.

Petzold, A., Hasselbach, J., Lauer, P., Baumann, R., Franke, K., Gurk, C., Schlager, H., and Weingartner, E.: Experimental studies on particle emissions from cruising ship, their characteristic properties, transformation and atmospheric lifetime in the marine boundary layer, Atmos. Chem. Phys., 8, 2387-2403, doi:10.5194/acp-8-2387-2008, 2008.

Pirjola, L.: Effects of the increased UV radiation and biogenic VOC emissions on ultrafine sulphate aerosol formation, J. Aerosol Sci., 30, 355-367, 1999.

Pirjola, L. and Kulmala, M.: Modelling the formation of $\mathrm{H}_{2} \mathrm{SO}_{4}$ $\mathrm{H}_{2} \mathrm{O}$ particles in rural, urban and marine conditions, Atmos. Res., 46, 321-347, 1998.

Pirjola, L., Tsyro, S., Tarrason, L., and Kulmala, M.: A monodisperse aerosol dynamic module, a promising candidate for use in long-range transport models: Box model tests, J. Geophys. Res., 108(D9), 4258, doi:10.1029/2002JD002867, 2003.

Ramankutty, N., Evan, A. T., Monfreda, C., and Foley, J. A.: Farming the planet: 1. Geographic distribution of global agricultural lands in the year 2000, Global Biogeochem. Cy., 22, GB1003, doi:10.1029/2007GB002952, 2008.

Robinson, A. L., Donahue, N. M., Shrivastava, M. K., Weitkamp, E. A., Sage, A. M., Grieshop, A. P., Lane, T. E., Pierce, J. R., and Pandis, S. N.: Rethinking organic aerosols: Semivolatile emissions and photochemical aging, Science, 315, 1259-1262, 2007.

Rogers, R. R. and Yau, M. K.: A Short Course in Cloud Physics $3^{\text {rd }}$ Edition, Pergamon Press, Oxford, Great Britain ISBN: 0-08034864-5, 1989.

Roldin, P., Swietlicki, E., Massling, A., Kristensson, A., Löndahl, J., Eriksson, A., Pagels, J., and Gustafsson, S.: Aerosol ageing in an urban plume - implication for climate, Atmos. Chem. Phys., 11, doi:10.5194/acp-11-5897-2011, 5897-5915, 2011.
Rolph, G. D.: Real-time Environmental Applications and Display sYstem (READY) Website (http://ready.arl.noaa.gov/index.php), NOAA Air Resources Laboratory, Silver Spring, MD, 8:26 AM, Tuesday, March 01, 2011.

Sander, S. P., Friedl, R. R., Golden, D. M., Kurylo, M. J., Moortgat, G. K., Keller-Rudek, H., Wine, P. H., Ravishankara, A. R., Kolb, C. E., Molina, M. J., Finlayson-Pitts, B. J., Huie R. E., and Orkin, V. L.: Chemical Kinetics and Photochemical Data for Use in Atmospheric Studies, Evaluation Number 15, NASA, 2006.

Seibert, P., Beyrich, F., Gryning, S.-E., Joffre, S., Rasmussen, A., and Tercier, P.: Mixing Height Determination for Dispersion Modelling, COST Action 710, Preprocessing of Meteorological Data for Dispersion Modelling, Report of Working Group 2, 1997.

Schauer, J. J., Kleeman, M. J., Cass, G. R., and Simoneit, B. R. T.: Measurement of Emissions from Air Pollution Sources 3. C-C Organic Compounds from Fireplace Combustion of Wood, Envir. Sci. Tech., 35, 1716-1728, 2001.

Schurgers, G., Arneth, A., Holzinger, R., and Goldstein, A. H.: Process-based modelling of biogenic monoterpene emissions combining production and release from storage, Atmos. Chem. Phys., 9, 3409-3423, doi:10.5194/acp-9-3409-2009, 2009a.

Schurgers, G., Hickler, T., Miller, P. A., and Arneth, A.: European emissions of isoprene and monoterpenes from the Last Glacial Maximum to present, Biogeosciences, 6, 2779-2797, doi:10.5194/bg-6-2779-2009, 2009b.

Seinfeld, J. H. and Pandis, S. N.: Atmospheric Chemistry and Physics: From Air Pollution to Climate Change, (2nd edition), Wiley, New Jersey, ISBN: 0-471-72018-6, 2006.

Sheehan, P. E. and Bowman, F. M.: Estimated Effects of Temperature on Secondary Organic Aerosol concentrations, Environ. Sci. Technol., 35, 2129-2135, 2001.

Shrivastava, M. K., Lane, T. E., Donahue, N. M., Pandis, S. N., and Robinson, A. L.: Effects of gas particle partitioning and aging of primary emissions on urban and regional organic aerosol concentrations, J. Geophys. Res., 113, D18301, doi:10.1029/2007JD009735, 2008.

Simpson, D., Fagerli, H., Jonson, J. E., Tsyro, S., Wind, P., and Tuovinen, J.-P.: Transboundary Acidification, Eutrophication and Groud Level Ozone in Europe, Part I, Unified EMEP Model Description, EMEP Status Report 2003, ISSN 0806-4520, 2003.

Sitch, S., Smith, B., Prentice, I., Arneth, A., Bondeau, A., Cramer, W., Kaplan, J., Levis, S., Lucht, W., Sykes, M., Thonicke, K., and Venevsky, S.: Evaluation of ecosystem dynamics, plant geography and terrestrial carbon cycling in the LPJ Dynamic Global Vegetation Model Global Change Biology, 9, 161-185, 2003.

Slinn, S. A. and Slinn, W. G. N.: Predictions for particle deposition on natural waters, Atmos. Environ., 14, 1013-1016, 1980.

Slinn, W. G. N.: Predictions for particle deposition to vegetation canopies, Atmos. Environ., 16, 1785-1794, 1982.

Smith, B., Prentice, I. C., and Sykes, M. T.: Representation of vegetation dynamics in the modeling of terrestrial ecosystems: comparing two contrasting approaches within European climate space, Global Ecol. Biogeogr., 10, 621-637, 2001.

Steinbrecher, R., Smiatek, G., Köble, R., Seufert, G., Theloke, J., Hauff, K., Ciccioli, P., Vautard, R., and Curci, G.: Intra- and inter-annual variability of VOC emissions from natural and seminatural vegetation in Europe and neighbouring countries, Atmos. Environ., 43, 1380-1391, 2009. 
Stokes, R. H. and Robinson, R. A.: Interactions in Aqueous Nonelectrolyte Solutions. I. Solute-Solvent Equilibrium, J. Phys. Chem., 70, 2126-2131, 1966.

Stohl, A., Haimberger, L, Scheele, M. P., and Wernli, H.: An intercomparison of results from three trajectory models, Meteorol. Appl., 8, 127-135, doi:10.1017/S1350482701002018, 2001.

Stull, R. B.: Meteorology for Scientists and Engineers, $\left(2^{\text {nd }}\right.$ edition), ISBN: 0-534-37214-7, 2000.

Svendby, T. M., Lazaridis, M., and Tørseth, K.: Temperature dependent secondary organic aerosol formation from terpenes and aromatics, J. Atmos. Chem., 59, 25-46, 2008.

Tarrasón, L., Turner, S., and Fløisand, I.: Estimation of seasonal dimethyl sulphide fluxes over the North Atlantic Ocean and their contribution to European pollution levels, J. Geophys. Res., 100, 11623-11639, 1995.

Tirabassi, T. and Rizza, U.: Boundary Layer Parameterization for a Non-Gaussian Puff Model, J. Appl. Meteorol., 36, 1031-1037, 1997.

Toon, O. B., McKay, C. P., Ackerman, T. P., and Santhanam, K.: Rapid Calculation of Radiative Heating Rates and Photodissociation Rates in Inhomogeneous Multiple Scattering Atmospheres, J. Geophys. Res., 94, 16287-16301, 1989.

Tsimpidi, A. P., Karydis, V. A., Zavala, M., Lei, W., Molina, L., Ulbrich, I. M., Jimenez, J. L., and Pandis, S. N.: Evaluation of the volatility basis-set approach for the simulation of organic aerosol formation in the Mexico City metropolitan area, Atmos. Chem. Phys., 10, 525-546, doi:10.5194/acp-10-525-2010, 2010.

Tunved, P., Ström, J., and Hansson, H.-C.: An investigation of processes controlling the evolution of the boundary layer aerosol size distribution properties at the Swedish background station Aspvreten, Atmos. Chem. Phys., 4, 2581-2592, doi:10.5194/acp-4-2581-2004, 2004.
Tunved, P., Partridge, D. G., and Korhonen, H.: New trajectorydriven aerosol and chemical process model Chemical and Aerosol Lagrangian Model (CALM), Atmos. Chem. Phys., 10, 10161-10185, doi:10.5194/acp-10-10161-2010, 2010.

Vestreng, V., Rigler, E., Adams, M., Kindbom, K., Pacyna, J. M., van der Gon, D., Reis, H. S., and Traynikov, O.: Inventory review 2006, Emission data reported to LRTAP and NEC Directive, Stage 1, 2 and 3 review and Evaluation of Inventories of HM and POPs, EMEP/MSC-W Technical Report 1/2006 ISSN 1504-6179, available from http://www.emep.int/, 2006.

Wang, F., Roldin, P., Massling, A., Kristensson, A., Swietlicki, E., Fang, D., and Ketzel, M.: Aerosol dynamics in the Copenhagen urban plume during regional transport, Atmos. Chem. Phys. Discuss., 10, 8553-8594, doi:10.5194/acpd-10-8553-2010, 2010.

Wesely, M. L.: Parameterization of surface resistance to gaseous dry deposition in regional-scale, numerical models, Atmos. Environ., 23, 1293-1304, 1989.

Wexler, A. S. and Clegg, S. L.: Atmospheric aerosol models for systems including the ions $\mathrm{H}^{+}, \mathrm{NH}_{4}^{+}, \mathrm{Na}^{+}, \mathrm{SO}_{4}^{2-}$, $\mathrm{NO}_{3}^{-}, \mathrm{Cl}^{-}, \mathrm{Br}^{-}$, and $\mathrm{H}_{2} \mathrm{O}$, J. Geophys. Res., 107(D14), 4207, doi:10.1029/2001JD000451, 2002.

Wexler, A. S. and Seinfeld, J. H.: The distribution of ammonium salts among a size and composition dispersed aerosol, Atmos. Environ., 24, 1231-1246, 1990.

Zaveri, R. A., Easter, R. C., Fast, J. D., and Peters, L. K.: Model for Simulating Aerosol Interactions and Chemistry (MOSAIC), J. Geophys. Res., 113, D13204, doi:10.1029/2007JD008782, 2008.

Zhang, L., Gong, S., Padro, J., and Barrie, L.: A size-segregated particle dry deposition scheme for an atmospheric aerosol module, Atmos. Environ., 35, 549-560, 2001.

Zhang, K. M. and Wexler, A. S.: Modeling urban and regional aerosols-Development of the UCD Aerosol Module and implementation in CMAQ model, Atmos. Environ., 42, 3166-3178, 2008. 